\title{
A complete workflow applied on an oil reservoir analogue to evaluate the ability of 4D seismics to anticipate the success of a chemical enhanced oil recovery process
}

\author{
Noalwenn Dubos-Sallée ${ }^{1}$, André Fourno ${ }^{1, *}$, Jeanneth Zarate-Rada ${ }^{1}$, Véronique Gervais ${ }^{1}$, \\ Patrick N. J. Rasolofosaon ${ }^{1}$, and Olivier Lerat ${ }^{2}$ \\ ${ }^{1}$ IFP Energies nouvelles, 1 et 4 avenue de Bois-Préau, 92852 Rueil-Malmaison Cedex, France \\ ${ }^{2}$ IFP School, 232 avenue Napoléon Bonaparte, 92852 Rueil-Malmaison, France
}

Received: 19 July 2019 / Accepted: 10 February 2020

\begin{abstract}
In an Enhanced Oil Recovery (EOR) process, one of the main difficulties is to quickly evaluate if the injected chemical products actually improve oil recovery in the reservoir. The efficiency of the process can be monitored in the vicinity of wells, but it may take time to estimate it globally in the reservoir. The objective of this paper is to investigate the ability of $4 \mathrm{D}$ seismics to bridge this gap and to help predict the success or breakdown of a production strategy at reservoir scale. To that purpose, we consider a complete workflow for simulating realistic reservoir exploitation using chemical EOR and 4D seismic modeling. This workflow spans from geological description to seismic monitoring simulation and seismic attributes analysis, through geological and reservoir modeling. It is applied here on a realistic case study derived from an outcrop analog of turbiditic reservoirs, for which the efficiency of chemical EOR by polymer and surfactant injection is demonstrated. For this specific field monitoring application, the impact of both waterflooding and proposed EOR injection is visible on the computed seismics. However, EOR injection induces a more continuous water front that can be clearly visible on seismics. In this case, the EOR efficiency can thus be related to the continuity of the water front as seen on seismics. Nevertheless, in other cases, chemical EOR injections may have more moderate impacts, or the field properties may be less adapted to seismic monitoring. This points out the importance of the proposed workflow to check the relevance of seismic monitoring and to design the most adapted monitoring strategy. Numerous perspectives are proposed at the end of the paper. In particular, experts of the different disciplines involved in the proposed workflow can benefit from the availability of a complete set of well-controlled data of various types to test and improve their own tools. In contrast, the non-experts can easily and quickly benefit from "hands-on" experiments for understanding the involved phenomena. Furthermore, the proposed workflow can be directly applied to geological reservoirs all over the world.
\end{abstract}

\section{Introduction}

Crude oil, representing more than $30 \%$ of energy demand, is still a major energy source for the current economics of the world (Manrique et al., 2010). Hence, to satisfy the increasing global energy demand and consumption, increasing effort must be devoted by the oil industry not only to identify new oil reservoirs, but also to improve the oil recovery from mature reservoirs. Primary oil recovery, by initial reservoir pressure depletion, hardly exceeds $20 \%$ of Original Oil in Place (OOIP). Water injection is applied in a secondary oil recovery to prevent depletion of the reservoir pressure and to recover more oil. However, more than roughly $65 \%$ of OOIP remains unswept after this stage.

\footnotetext{
* Corresponding author: andre.fourno@ifpen.fr
}

In the next step, often referred to as tertiary oil recovery, Enhanced Oil Recovery (EOR) or Improved Oil Recovery (IOR), a substance that is not present in the reservoir is injected in order to further increase oil recovery (e.g., Cossé, 1993; Green and Willhite, 1998; Lake et al., 2014).

Among the existing techniques, chemical based EOR including synergetic combination of surfactant, polymer and alkali has been well documented either in laboratory studies (e.g., Bourbiaux et al., 2015; Hou et al., 2005; Leray et al., 2016), in simulation studies (e.g., Douarche et al., 2012, 2014; Zerpa et al., 2005) or in pilot tests (Delamaide et al., 2014; Demin et al., 1997; Vargo et al., 2000). Due to the cost of injected chemical products, various tests are performed prior to field injection to estimate the efficiency of the chosen products at reservoir scale and to optimize the production scheme. Experiments are first conducted 
at core scale (Borozdina et al., 2019). They provide an idea of the oil recovery that can be expected at the field scale. As the reservoir heterogeneity can strongly affect the efficiency of the EOR strategy, it needs to be also estimated and optimized at larger scales - pilot and field scales - prior to production. This can be achieved using numerical models representing the reservoir.

To be as representative as possible, these models should be constrained to all available data. In particular, they should reproduce the production measurements acquired at wells such as pressure and injection/production rates. However, these data may not be informative enough to properly constrain all the model parameters, such as petrophysical properties. As a result, the production forecasted by the models in response to a given development plan may differ from the one that would be observed if actually producing the reservoir following this strategy. It is thus necessary to check the in-situ efficiency of the EOR process as soon as possible after the beginning of chemical product injection to avoid useless injection of costly products. Single-well chemical tracer tests can provide information in the vicinity (few meters) of the injection wells (Cockin et al., 2000; Deans, 1971; Deans and Carlisle, 2007). Oil production measurements can also be used, but the impact on these data may take time to become clearly visible depending on the reservoir properties and well location. It would thus be interesting to identify a monitoring technique able to provide information on the efficiency of the EOR strategy away from the wells and in a short time frame after the beginning of injection. The associated measurements could also be compared to the corresponding simulated values and used if necessary to update the reservoir model.

Time-lapse seismics or $4 \mathrm{D}$ seismics, naturally comes to mind as a potential method. 4D seismics involves acquisition, processing and interpretation of repeated seismic surveys over a field during its exploitation. The objective is to determine the changes occurring in the reservoir by comparing the repeated datasets (e.g., Calvert, 2005; Johnston, 2013). This method moved from a research experiment tool in the mid-1980s to a mature technology now widely used for instance to monitor subsurface exploitation for assisting reservoir management and field development. A detailed description of this technology is beyond the scope of the present paper and can be found in the two previous references. However here we shall introduce the three main high values of $4 \mathrm{D}$ seismics unambiguously demonstrated by field achievements.

The first one is the ability to locate by-passed oil and undrained reserves. This has been observed in most of the major oil fields where 4D seismics have been applied, either in the Gulf of Mexico on Hoover, Madison or Marshall fields (e.g., Helgerud et al., 2011), in the North Sea (e.g., Koster et al., 2000; Landro et al., 1999), or in offshore West Coast of Africa (e.g., Lumley et al., 1999; Onuwaje et al., 2009). Identifying undrained compartments is the second value of $4 \mathrm{D}$ seismics. For instance, on the Gullfaks field in Norwegian North Sea, 4D seismics helped to identify not only production related changes of seismic amplitudes but also un-swept zones in the reservoir. Later, two wells were drilled in the zones identified as undrained by $4 \mathrm{D}$ seismics. Not only both wells encountered oil filled reservoirs but also well data confirmed the waterfront movement predicted in the reservoir (Landro et al., 1999). The last main value of $4 \mathrm{D}$ seismics that we shall consider is its ability to optimize the infill drilling program. For instance, on Draugen field offshore Norway, the flow model was updated manually to predict the performance of the planned infill at several alternative locations. 4D seismics contributed to find the optimal location that differs from the originally planned location. A straightforward consequence was the resulting delay in anticipated water cut which extended the forecasted plateau production and increased the predicted recovery (Koster et al., 2000). Most of these values are confirmed in the case considered in the present work.

In this paper, we thus propose to address the question of the ability of $4 \mathrm{D}$ seismics to characterize the impact of a chemical product injection in an oil reservoir. More specifically, we propose to compute 4D seismic cubes for different production strategies on a given reservoir to see if characteristic features can be identified and related to each strategy. This appears as an important preliminary step before real seismic data acquisition to avoid useless and costly measurements and to design the most informative 4D survey. The computation of the seismic response is performed here with the workflow described in Figure 1. It consists of geological and reservoir modeling, flow simulation, rock physics modeling of the petroelastic properties, and seismic modeling, processing and seismic attribute analysis. This workflow was already partially considered for various applications. For instance, geological modeling and reservoir simulation are considered on a polymer flood pilot in Delaplace et al. (2013). These two steps are complemented with impedance variation computation in Roggero et al. (2012), Le Ravalec et al. (2012), and Tillier et al. (2012), considering reservoirs produced by water or gas injection, and SAGD process.

Our study focuses on the application of the workflow on Ainsa-1 quarry outcrop (South-central Pyrenean foreland basin in Spain), a well-known analog of turbiditic reservoirs offshore West Africa (e.g., Arbués et al., 2007; Falivene et al., 2006b; Pickering et al., 2015). Outcrop analogs have been studied for decades to constrain the physical geological properties of subsurface reservoirs and better understand depositional environments at the origin of petroleum systems and their architectures (Pringle et al., 2006). Outcrop analog studies help hydrocarbon exploration as they provide detailed characterizations of geology and facies distribution that can be used to improve seismic dataset interpretation and fluid dynamic understanding (Massonnat et al., 2017). Models built from outcrop studies can be used to generate synthetic seismic data which can serve in turn as training tools for seismic interpretation or can be compared to real seismic-reflection data acquired on the field of interest (Armitage and Stright, 2010; Bakke et al., 2013; Bourgeois et al., 2004; Doherty et al., 2002; Falivene et al., 2010; Holgate et al., 2014; Janson and Fomel, 2011; Schmitz et al., 2014; Schwab et al., 2007; Stright et al., 2014). The quality of 3D facies models built from outcrop analogs is also evaluated through the ability of such models to 


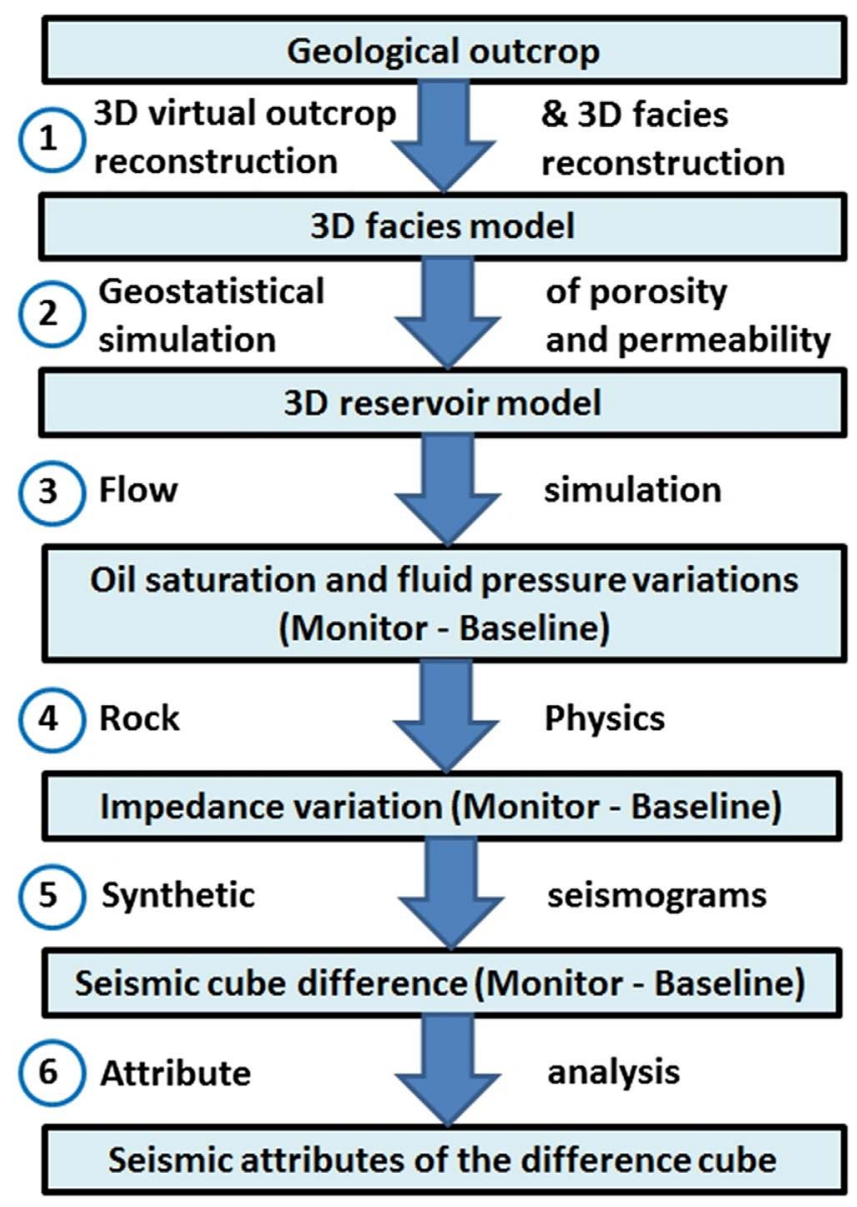

Fig. 1. The complete workflow.

reproduce or predict the dynamic flow behavior of subsurface related systems (Adams et al., 2011; Falivene et al., 2006a; Schmitz et al., 2014). Reservoir dynamic simulations performed on static models from outcrop analog studies are an excellent way to understand the impact of good-reservoir and non-reservoir rock-type distributions on sweep efficiency for instance (Adams et al., 2011). It is also a very interesting way to test the effects of different scales of modeled heterogeneity on production (Falivene et al., $2006 \mathrm{~b}$ ) and/or to optimize well placement in the related types of reservoirs (Stright et al., 2014). So our work benefited from previous studies of this outcrop (Arbués et al., 2007; Falivene et al., 2006b; Schmitz et al., 2014) and strongly emphasized the integration of the various fields of expertise involved in this workflow; for instance in Virtual analog (e.g., Schmitz et al., 2014), in Geological modeling (e.g., Gasparrini et al., 2016), in Reservoir simulation \& history matching (e.g., Le Ravalec et al., 2012), in 4D seismic inversion (e.g., Labat et al., 2012) and in Rock Physics (e.g., Rasolofosaon and Zinszner, 2012, 2014).

The paper outline is as follows. First, we detail the geological and reservoir modeling steps of the proposed integrated workflow. Then, we describe the flow simulation part and the results obtained with two injection strategies: a chemical EOR process, namely Surfactant-Polymer (SP) injection, and the more conventional Water-Flooding (WF). Contributions of $4 \mathrm{D}$ seismics to anticipate the success or breakdown of the chemical EOR strategy are then developed. The last sections are dedicated to discussions on the achievements of the proposed workflow, and to some concluding remarks and possible extensions of this work.

\section{Geological and reservoir modeling}

The model is constructed from the numerous geological observations on an outcrop located close to Ainsa town, in southern Pyrenees, Spain. This outcrop has been extensively studied as an analog of reservoirs offshore West Africa, and more generally for the overall understanding of turbidite systems (e.g., see Arbués et al., 2007; Pickering et al., 2015). Using internal software (OpenFlow Suite, 2015/2016) and an adapted workflow, we benefited from the extensive work of Schmitz et al. (2014) for achieving a high resolution $3 \mathrm{D}$ virtual reconstruction of the outcrop using photogrammetric methods. The dimension of the outcrop is about $40 \mathrm{~m}$ thick and $750 \mathrm{~m}$ wide. It is oriented NNW-SSE, oblique to the mean paleoflow estimated towards WNW.

The Ainsa-1 turbidite system is subdivided into three cycles of channel-complex development and abandonment. Channel complexes are composed of closely stacked channel forms of several meters thick to $20 \mathrm{~m}$ thick (Fig. A1 of Appendix A). Based on geological interpretation and outcrop studies, the outcrop section is divided into five sedimentary zones by six bounding horizons. This division is based on erosional surfaces of turbidite channels, because their filling is multistory and includes facies associations that represent various degrees of erosion and sediment bypass by turbidity currents (e.g., Arbués et al., 2007).

Five facies were identified by Arbués et al. (2007), namely from the more to the less permeable, thick-bedded sandstone, heterolithics, conglomerate, mudstone clast conglomerate, and gravelly mudstone. Conglomerate and mudstone clast conglomerate are up to 1-m thick while thick-bedded sandstone has sandstone beds thicker than $10 \mathrm{~cm}$ and heterolithics have finer sandstone beds (up to $10 \mathrm{~cm}$ ). More details are given in Appendix A.

The facies model is built on the same geological grid as in Jardin et al. (2010). It is defined according to the five sedimentary zones, and consists of about 650000 active cells of size $15 \mathrm{~m} \times 15 \mathrm{~m}$ in the horizontal direction. Vertical cell size is not constant and equals $0.5 \mathrm{~m}$ on average. The vertical resolution is thus adapted to correctly model facies distribution except for heterolithics for which hypotheses (in terms of permeability, porosity...) have to be made to model the impact of mudstone beds contained in this facies. Facies proportions are deduced from four vertical sedimentological sections selected across the outcrop (Appendix A) also used to build the facies model obtained by Jardin et al. (2010). To obtain more spatially distributed data, four additional synthetic vertical logs (Fig. A3) were extracted from this facies model and used together with the previous data to generate a new model in the present work. The geostatistical approaches used for this simulation are 

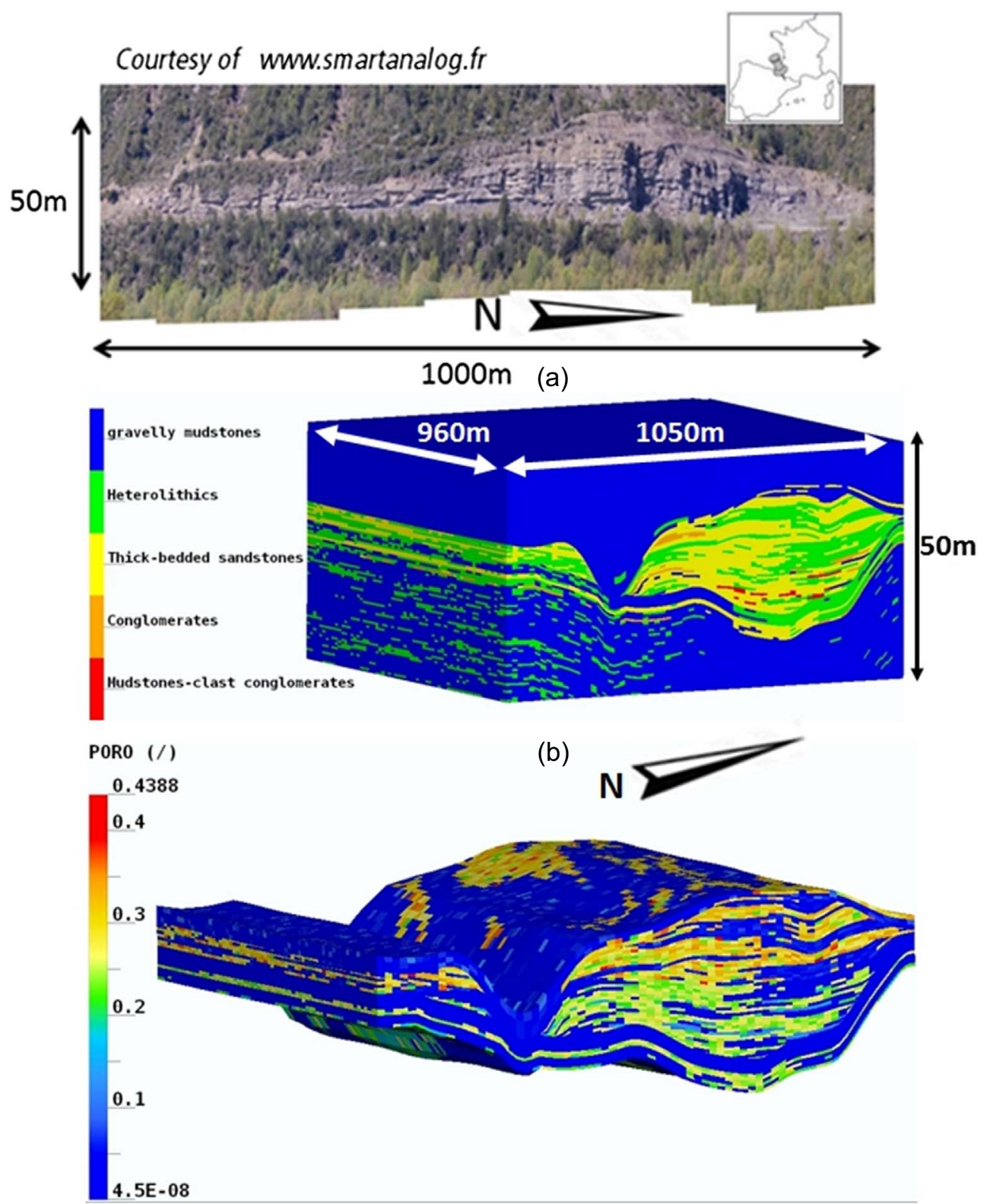

(c)

Fig. 2. (a) Geological outcrop, (b) 3D facies model, and (c) 3D porosity model.

the Truncated Gaussian method (Doligez et al., 1999; Galli et al., 1994) for units $\mathrm{C} 1$ and $\mathrm{C} 2.2$, and the sequential indicator simulation for units $\mathrm{C} 2.1$ and C3 (Fig. A1b). These geostatistical approaches have already been applied successfully in many depositional settings, including deep offshore settings (Jardin et al., 2010; Lerat et al., 2007). Referring to Falivene et al. (2006a), the values for major, minor and vertical direction ranges of variograms were considered to be the same for all facies, $500 \mathrm{~m}, 100 \mathrm{~m}$, and $0.5 \mathrm{~m}$ respectively, with an azimuth parallel to the paleoflow direction for both approaches.

In Schmitz et al. (2014) and Falivene et al. (2006b), constant petrophysical properties were attributed to each facies. In our study, porosity and permeability are considered as random functions defined per facies. Truncated Gaussian distributions are used for porosity and truncated lognormal distributions for permeability. The geostatistical characteristics (e.g., mean and variance as detailed in Appendix A) were chosen to be representative of analogous subsurface turbidite reservoirs while being relevant to induce impacts on chemical EOR. We wanted to induce contrasted permeabilities between the thick-bedded sandstone and the heterolithics to highlight flow layering reduction thanks to chemical product injection. Figure 2c shows the resulting 3D porosity model. Figure 3a illustrates the statistical distribution of porosity and horizontal 


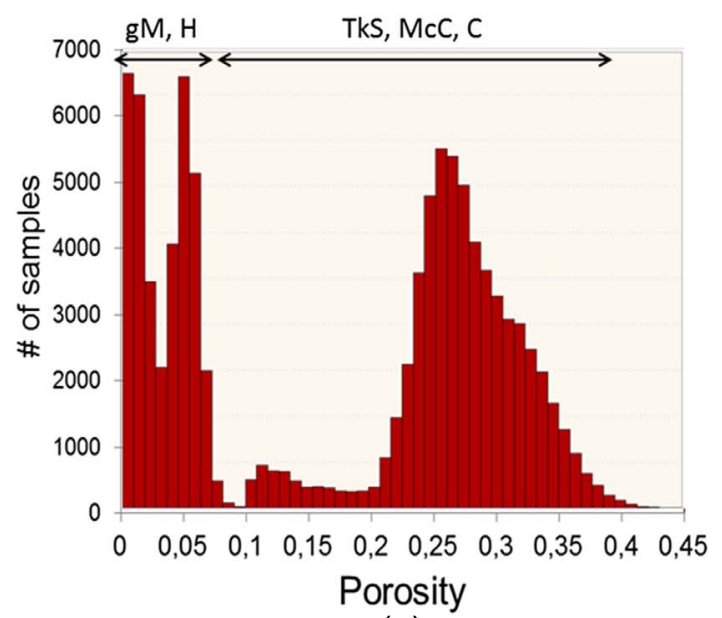

(a)

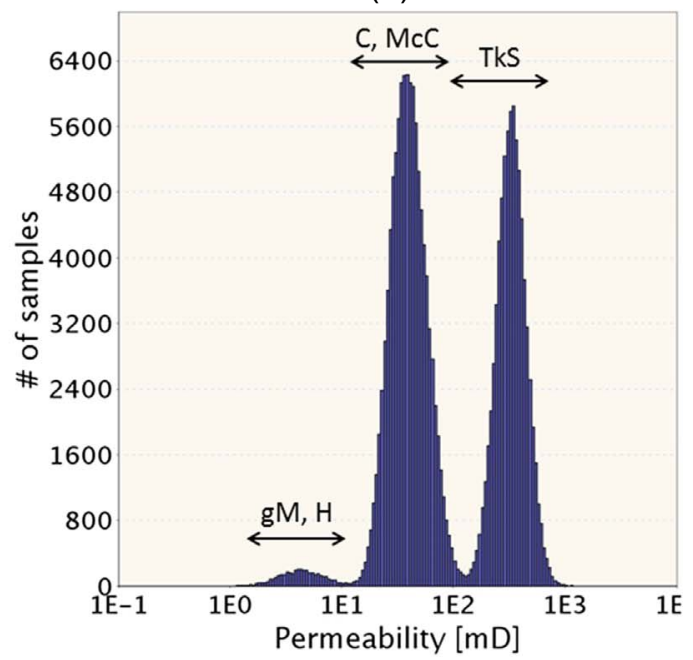

(b)

Fig. 3. Histograms of (a) porosity and (b) horizontal permeability. The different facies are identified by their nomenclature: gravelly mudstone $(\mathrm{gM})$, heterolithics $(\mathrm{H})$, thick-bedded sandstone $(\mathrm{TkS})$, mudstone-clast conglomerates $(\mathrm{McC})$ and conglomerates (C).

permeability (Fig. 3b). Facies are indicated using the nomenclature of Arbués et al. (2007) introduced previously.

The most porous/permeable facies (typical porosity $\phi>0.10$ and horizontal permeability $k_{H}>10 \mathrm{mD}$ ) are the thick-bedded sandstone, the conglomerates, and, to a lesser extent, the mudstone-clast conglomerates. The other facies, namely heterolithics and gravelly mudstone, are substantially less porous/permeable, within the reservoir and in the main E-W channel. Each facies permeability is assumed isotropic except for heterolithics and mudstone-clast conglomerates for which the vertical permeability is correlated to the horizontal one using a factor of 0.1 and 0.05 respectively because of mudstone beds or inclusions. For comparison, Figure 4 shows horizontal slices of the facies, porosity, and horizontal permeability models, located approximately halfway up the reservoir. The presence of a channel filled by debris-flow deposits in the southern part is represented by a narrow zone of quite low porosity/permeability.
Usually, at this stage, an upscaling of petrophysical properties from the fine geological scale to the coarse reservoir scale is performed in order to speed up flow simulations (e.g., Iske and Randen, 2006). Here, the size of the model makes it quite manageable for computation, so that no upscaling was performed. Thus, in our case, the reservoir grid was identical to the geological grid. We are aware that the flow simulations are usually performed at a coarser scale than geological modeling, mainly because of computation cost. Here we perform flow simulations at the same scale in order to point out subtle effects such as layering effect due to the heterogeneity of facies and permeability distributions in the reservoir as will be detailed further. This will allow a refined interpretation of the seismic response, and as a consequence of the seismic visibility analysis. Regarding the impact of the flow simulation on the seismic visibility analysis, we expect that the randomness and the characteristic statistical lengths of the studied media have a direct influence on the answer. In other words, more homogeneous media do not necessitate flow simulation at a fine scale. Beyond such elementary consideration, we agree that a detailed analysis of the impact of the flow simulation grid resolution on seismic feasibility analysis would be a research topic in itself but is beyond the scope of the present work. Finally, average compressibility values are assigned to each facies in order to compute the pressure field during flow simulation. Rock bulk modulus is of the order of a few GPa to tens of GPa (Rasolofosaon and Zinszner, 2012), which corresponds to compressibility of the order of $10^{-4}-10^{-5} \mathrm{bar}^{-1}$ (details can be found in Appendix A). We chose an average reservoir depth of $2200 \mathrm{~m}$ corresponding to an average overburden weight of 600 bars, roughly three times the hydrostatic pressure. The initial fluid pressure was then 253 bars and the reservoir temperature was $83^{\circ} \mathrm{C}$.

As far as fluid composition is concerned, the reservoir is naturally saturated with an oil characterized by an average density of $853.7 \mathrm{~kg} / \mathrm{m}^{3}$ (approximately corresponding to API gravity of 34) at surface conditions (the water-oil contact is located below the reservoir). For flow simulation (step 3 in Fig. 1), we assume a two-phase saturating fluid with oil and water (average density of $1012 \mathrm{~kg} / \mathrm{m}^{3}$ at surface conditions), but no gas. Furthermore, the dependence of fluid properties required for flow simulation is given in Appendix A. Relative permeability curves and capillary pressure curves are typical of water wet rocks. For all facies, water saturation varies between $30 \%$ and $68 \%$ except for sandstone in which water saturation varies from $15 \%$ to $75.5 \%$. Although relative permeability and capillary pressure end-point values are the same for all facies, the different irreducible oil and water saturations make the sandstone facies the best one in terms of oil volume storage and facility to produce it. More details, and in particular endpoint curve values, are given in Appendix A.

\section{Flow simulation and injection strategies}

As illustrated in Figure 5, the production pattern was an inverted five-spot (e.g., Lyons and Plisga, 2011), with a single injection well surrounded by four producers. 


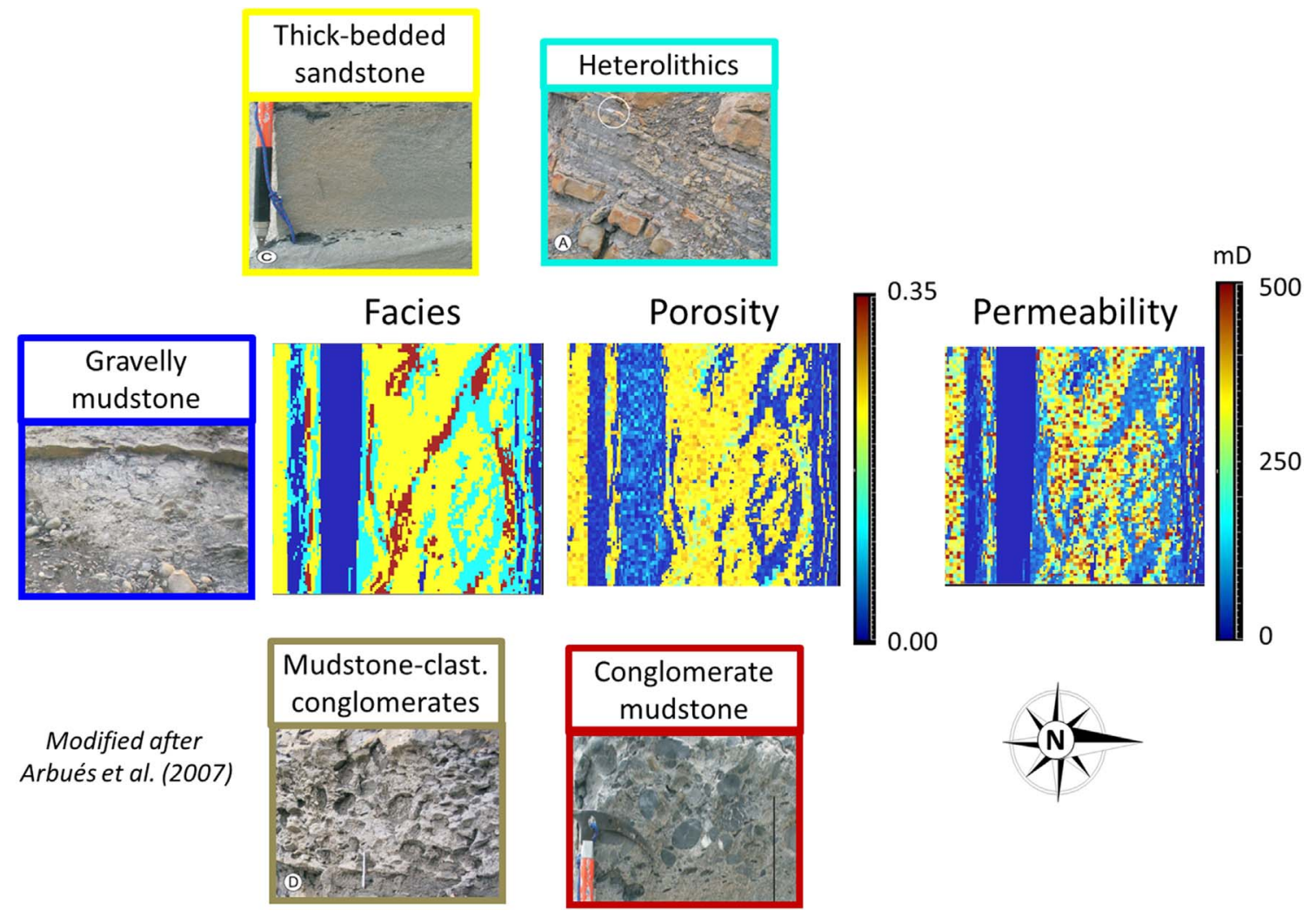

Fig. 4. Correspondence between the 3D facies model, 3D porosity model and 3D horizontal permeability model at a fixed depth in the reservoir. Illustrative photographs (modified from Arbués et al., 2007) of the different facies are framed with the corresponding color in 3D facies model.

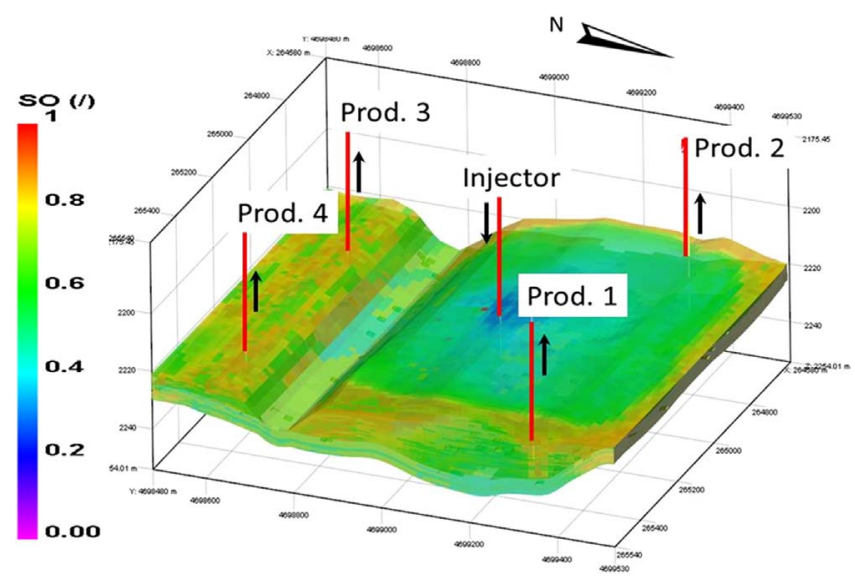

Fig. 5. Sketch of the inverted 5 -spot injection pattern. Oil saturation (SO) after 14 years of water flooding.

The production wells were located roughly in the corners of the model, two of them being placed south of the main E-W channel and aligned with the channel axis. The injector well, at the center of the pattern, was located to the north of the channel. Such a configuration allows us to check the possible compartmentalization of the reservoir due to the presence of the main E-W channel. Productivity indices for these wells were classically estimated by the method of Peaceman (1983). Injection and production were imposed target maximum rate constraints $\left(Q_{\max }=\right.$ $600 \mathrm{~m}^{3} \mathrm{~d}^{-1}$ for the injector and $150 \mathrm{~m}^{3} \mathrm{~d}^{-1}$ for each producer, see details in Appendix B) with a switch to pressure control if the pressure limit was reached (maximum pressure at the injector and minimum pressure at the producer). Pressure constraint at injectors aims at protecting both wells and reservoirs from mechanical damages while for producers, this pressure limit is a flow requirement to the production facilities. Such a switch to pressure control was observed here at the injector at the beginning of polymer injection (see Appendix B). More precisely, the injector pressure increased to the maximum authorized pressure, and was then kept below or equal to this limit pressure by decreasing when necessary the water injection rate.

The spatial distribution of oil saturation in the reservoir after 14 years of water flooding is shown in Figure 5 . Even after such a long time, some areas have been hardly swept, with an oil saturation as high as 0.8 . This is the case for instance to the south of the E-W channel (near producers $\# 3$ and $\# 4)$ and in the vicinity of well $\# 1$. The presence of the major E-W channel contributes to compartmentalize the southern part of the reservoir. That will be confirmed by time-lapse seismics in the next section. Furthermore, long-range heterogeneity features, such as 


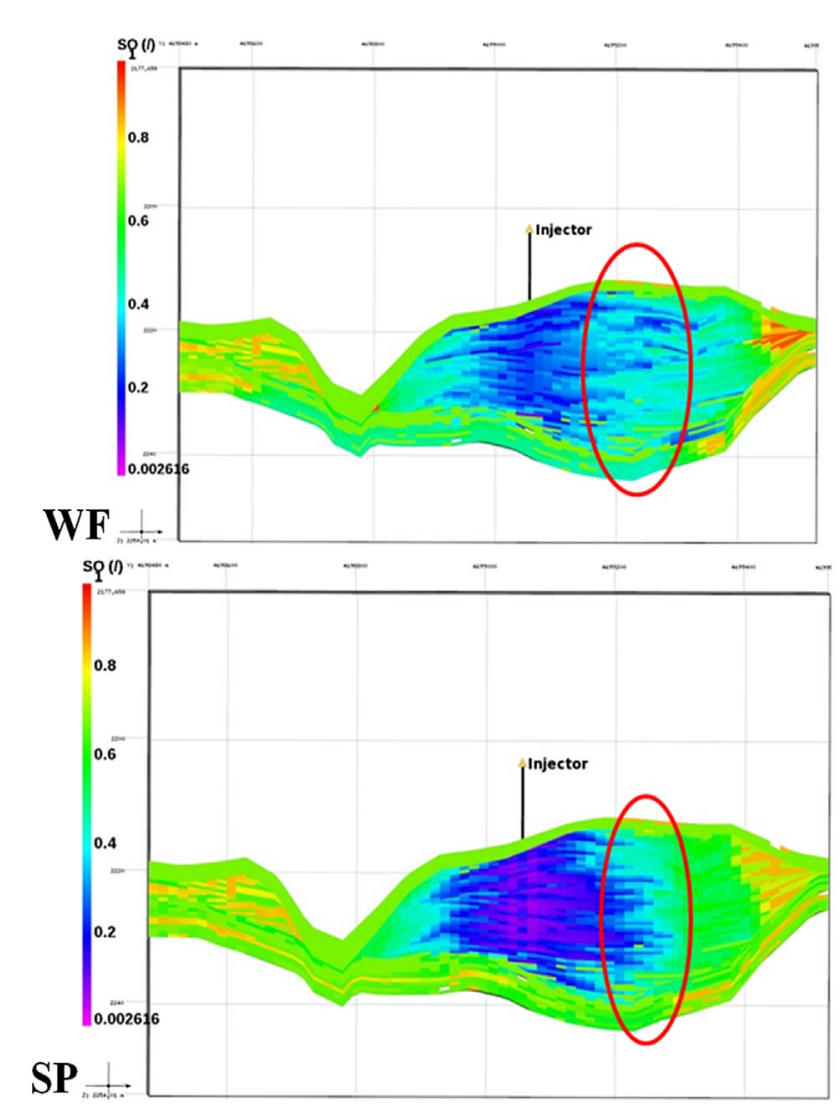

Fig. 6. Vertical NS cross-section of oil saturation after 42 months $(01 / 01 / 2020)$ for the two injection strategies (WF, SP). Red ellipses point out the layering effect due to the heterogeneity of facies and permeability distributions in the reservoir (WF) and the decrease of this layering effect, depending on SP injection.

vertical interbedded contrasts, have significant effects on flow behavior. This is visible on the top of Figure 6 showing a vertical NS cross-section of oil saturation simulated after only 42 months of water-flooding. The red ellipse points out a layering effect due to the facies heterogeneity and the associated petrophysical property distributions in the reservoir.

This layering effect and the large volume of oil remaining in the reservoir at the end of the water-flooding process gave support to our interest in studying the ability of chemical EOR to improve areal sweep efficiency. Different chemical EOR scenarios with various types of combinations of alkaline (A), surfactant (S), and polymer (P), namely $\mathrm{P}$, $\mathrm{S}, \mathrm{SP}, \mathrm{AS}$, and ASP were tested and compared to a conventional water-flooding. A detailed description of the results is beyond the scope of this work but can be found in ZarateRada (2016). Here, we only focused on the two injection strategies described in Figure 7: Polymer-Surfactant (SP) injection and pure Water-Flooding (WF).

In both cases, water injection started in April 2016. The EOR process started a year later, in April 2017, just after an early water breakthrough. Figure 8 compares the two scenarios in terms of cumulative oil production and water cut during the 14 years of production.

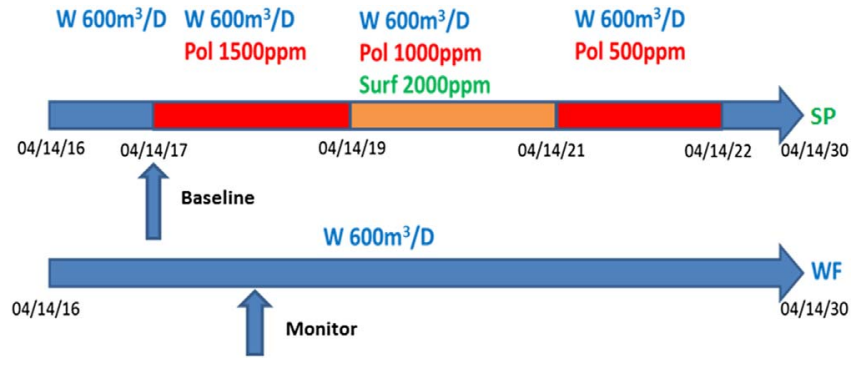

Fig. 7. The two injection scenarios. SP injection consists of a water flooding period followed by polymer $(\mathrm{Pol})$ and surfactant (Surf) injection according to the indicated concentrations. Appendix B provides details on water injection rates along time due to the competition between the imposed target maximum injection rate on one side, and maximum pressure constraint at the injector on the other side. Note also that Baseline time $(04 / 04 / 2017)$ and Monitor time (04/14/2018) are indicated on the time frame.

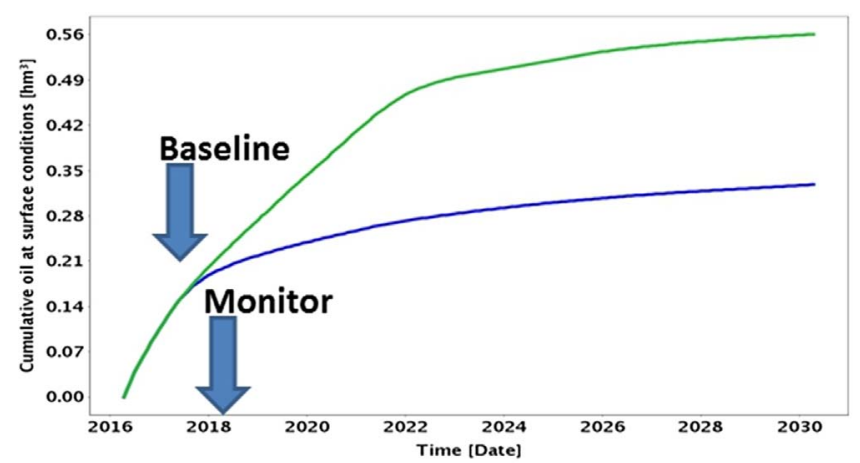

(a)

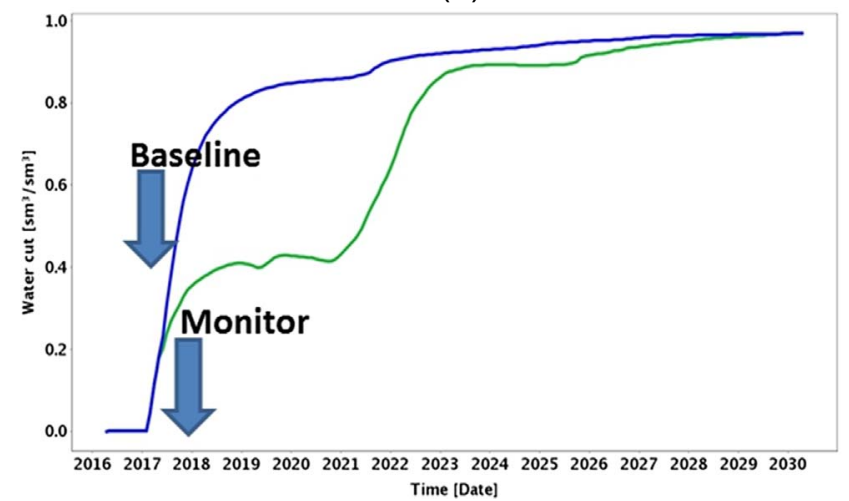

(b)

Fig. 8. (a) Cumulative oil production and (b) water cut for the two processes: Water Flooding (WF) in blue and EOR injection (SP) in green.

The curves corresponding to WF and SP are plotted in blue and green, respectively. As expected, the SP scenario induced a better recovery than simple water-flooding, with a strong reduction of the water cut and a larger cumulative oil production. As illustrated in Figure 6, this improvement is due to a decrease of the flow layering induced by the 
higher viscosity of the injected fluid leading to a reduction of mobility.

Performing this kind of comparative numerical studies is a classical step to estimate the added value of a given chemical formulation and injection strategy compared for instance to water flooding. However, these tests are based on a numerical model that, although calibrated on the available data (oil production, water cut, bottom hole pressure...), may provide production forecasts that differ from the real behavior. The in-situ efficiency of the EOR process should thus be checked as soon as possible after the beginning of injection. In practice, the impact on the reservoir production observed from the wells may take time to become clearly visible depending on the reservoir properties and well locations. We thus propose to evaluate the ability of $4 \mathrm{D}$ seismics to assess the efficiency of the EOR strategy at an early stage of the process, close to the beginning of injection.

\section{Synthetic time-lapse seismic response}

Two specific calendar times, namely Baseline (04/04/2017) and Monitor (04/14/2018), are chosen to compute the timelapse seismic response. Baseline calendar time corresponds to the beginning of polymer injection. Monitor calendar time was chosen one year after (Fig. 7). The time-lapse seismic response is computed based on petroelastic properties derived from the pressure and fluid saturation variations. In the following sections, the impact of the SP scenario on these intermediary properties is analyzed prior to conclude on the seismic response itself. The idea is to make the link between the characteristic features identified from the reservoir properties and the seismic attributes.

\subsection{Pressure and oil saturation}

To obtain a numerical estimation of time-lapse seismic response, pressure, and oil saturation have first to be obtained at the two dates from the flow simulations described in the previous section. Figure 9 displays the changes in the reservoir pressure and oil saturation in response to the two injection strategies. Note that the representation in difference cubes (Monitor - Baseline) was usually preferred to the representation in monitor cubes in order to magnify the visualization of the production process signature (e.g., Calvert, 2005; Johnston, 2013). Each sub-figure shows a horizontal slice of the considered 3D difference cube, at Monitor calendar time. The upper series corresponds to $\mathrm{WF}$ and the lower one to SP process, while the first column corresponds to the variation of oil content $\Delta S_{\mathrm{o}}$ and the second one to the variation of fluid pressure $\Delta P$.

Let us notice the complicated pattern of the spatial distribution of oil content $\Delta S_{\mathrm{o}}$ for both injection strategies, mainly due to the reservoir heterogeneity. The signature of a horizontal spatial correlation of facies, porosity and permeability roughly in the SE-NW direction seen in Figure 4 can be retrieved in the $\Delta S_{0}$ distributions in Figure 9, with alternating zones of increasing (light yellow) and decreasing saturation (light green). In addition, switching from water

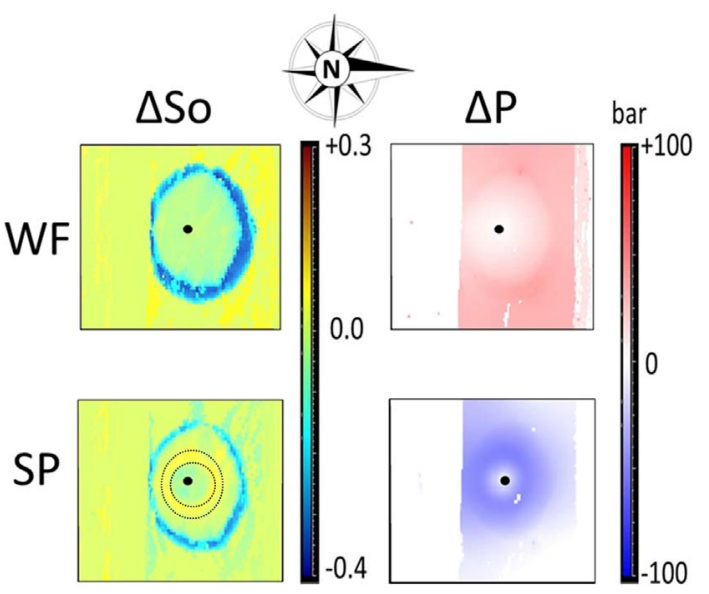

Fig. 9. Horizontal cross-sections halfway up the reservoir Influence of the process, namely Water flooding (top line) and EOR injection (SP) (bottom line) on the variations of oil saturation (1st column), fluid pressure (2nd column). The black dot on the maps of oil saturation and fluid pressure variations indicate the location of the injection well. The two doted circles (on the SP oil saturation variation map) highlight a local oil saturation increase due to the sweeping of additional oil.

flooding to polymer injection induced a substantial change in the spatial distribution of both $\Delta P$ and $\Delta S_{0}$. For oil saturation, the light green area around the injector well in the case of water-flooding corresponds to the area swept during the first year of water injection (before Baseline calendar time). This region was swept a little bit more by water during the second year of production (between Baseline and Monitor calendar times), while the area newly swept during this period appears in blue. Of course, for SP, the size of the area swept before Baseline calendar time is the same as for $\mathrm{WF}$, but the oil saturation variation inside this zone becomes significantly different after polymer injection. In particular, the yellow ring near the injector (and located between the two doted circles) corresponds to a local oil saturation increase due to the sweeping of additional oil which had been mobilized in the direct vicinity of the injector since the beginning of polymer injection. The spatial distribution of the fluid pressure variation $\Delta P$ is substantially smoother than the one of $\Delta S_{\mathrm{o}}$. This is a classical result due to the fact that pressure variations follow diffusion processes which induce quite smooth spatial variations (e.g., Bear, 1972; Cossé, 1993; Houpeurt, 1975; Muskat and Wyckoff, 1937). Another clear result is the positive pressure variation $\Delta P$ for $\mathrm{WF}$, which contrasts with the negative $\Delta P$ for SP. This result, unintuitive at first sight, can be explained by the different water injection rates for the two scenarios (WF and SP). Indeed, as polymer is less movable than water, polymer injection induced an increase of pressure at the injector compared to water flooding. The maximum authorized pressure was reached in this case so that the water injection rate decreased for the SP scenario, while remaining constant in the WF scenario (see Appendix B). Concomitantly, the area already swept by water before Baseline calendar time became an underpressure zone due to this decrease of water injection rate 


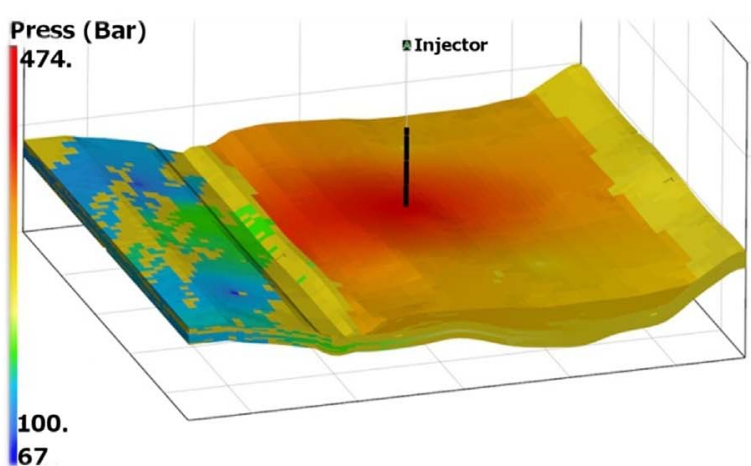

(a)

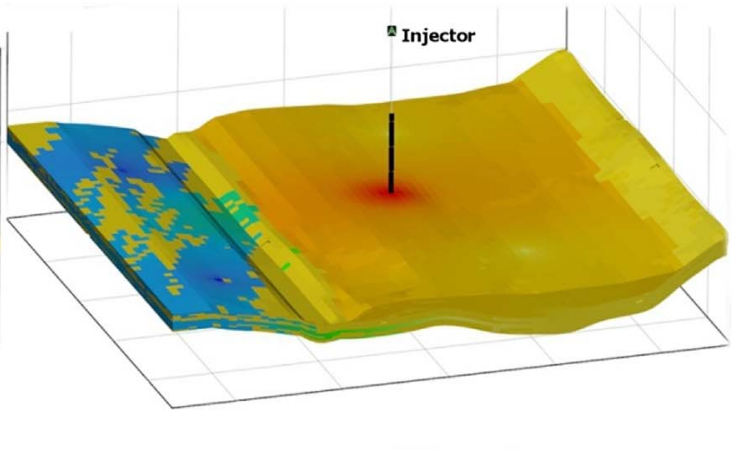

(b)

Fig. 10. (a) Field pressure at baseline and (b) at monitoring calendar times for SP injection strategy.

without changes of the production rates. As a result, pressure in this zone decreased during polymer injection (Fig. 10), leading to a negative $\Delta P$ between Baseline and Monitor calendar times.

This phenomenon also explains the fact that the SP waterfront at Monitor calendar time is closer to the injector well than the WF waterfront. Nevertheless, despite the change in injection strategy between WF and SP, the yellow ring is really associated with polymer injection. In this modeling, certain areas have already been swept on the Baseline date with a strong layering effect. As the injected water flows preferentially inside the swept zones (physical effect of water/oil diphasic flow), a hypothetic reduction in the injection rate for the WF case, as observed for SP, would not succeed in mobilizing additional oil. For SP case, the polymer also flows inside these swept zones but partially obstructs them, and then helps to better sweep neighboring areas. If the injection rate was smaller, the layering effect would be smaller at the Baseline date. In this case water would sweep the reservoir better while the polymer would be less efficient (this point is discussed in Sect. 5).

We now propose to check whether these differences in pressure and saturation variations also induce different characteristics on the petroelastic attributes.

\subsection{Petroelastic modeling}

The petroelastic modeling (step 4 in Fig. 1) is the key element to obtain a numerical modeling of the time-lapse seismic response. During this step, fluid properties (pressure, saturations, fluid densities, fluid elastic properties) and rock properties (porosity, matrix elastic properties) are converted into simulated elastic responses $(\mathrm{P}-$ and S-wave velocities, impedances) which are used to build the seismic responses (seismic amplitudes and other relevant seismic attributes). Previous studies proposed seismic models from outcrops-derived $3 \mathrm{D}$ facies models of the Eocene Ainsa turbidite systems (Falivene et al., 2010; Schmitz et al., 2014), but since they did not couple flow and seismic modeling for monitoring purposes, constant elastic velocities and densities were assigned to each facies. In contrast, in our study, the variations of seismic properties of the reservoir at any point due to fluid substitution and pressure variations induced by production were computed using Biot-Gassmann type of petroelastic model (e.g., Rasolofosaon and Zinszner, 2012). As detailed in Appendix $\mathrm{C}$, the model takes into account facies average petroelastic parameters as well as the pressure dependence of fluid and rock densities and elastic properties (see Figs. C1-C3 in Appendix C). In summary, fluid substitution (oil by water in this case) induces substantially larger variations of the fluid-saturated rock bulk modulus $M^{\text {(sat) }}$ than fluid pressure variations. For instance, pressure-induced variation of $M^{\text {(sat) }}$ hardly exceeds $5 \%$ for heterolithics, and even $1.5 \%$ for thick-bedded sandstone, in the most extreme case, namely in the case of full-oil saturation $\left(S_{\mathrm{o}}=1-S_{\mathrm{wi}}\right)$ (see Fig. C3 in Appendix C). In contrast, the variations of $M^{\text {(sat) }}$ induced by saturation changes due to the substitution of oil by water can reach up to $23 \%$ for thick-bedded sandstone and $20 \%$ for heterolithics.

Furthermore, the reservoir rock response to simultaneous fluid substitution and fluid pressure variation is intricate due to two competing effects. On the one hand, an increase of the fluid pressure $P_{p}$, implying a decrease of the differential pressure $P_{\text {diff }}$ at fixed confining pressure $P_{c}$, tends to soften the rock (decrease of the bulk modulus) by opening the cracks and compliant pores. On the other hand, an increase of the fluid pressure $P_{p}$ tends to increase the fluid bulk modulus of the saturating fluid, as illustrated by Figure C1, which stiffens the fluid-saturated rock. Depending on the level of oil saturation and on the considered rock, an effect dominates more or less the other one. In such cases, phenomena are so intricate that intuition is not sufficient. This highlights the need for a complete numerical computation in the framework of the proposed integrated workflow. This is all the more true that additional complexity induced by the presence of substantial heterogeneity is ubiquitous in the model.

From Biot-Gassmann theory for fluid substitution and Hertz-type theory for pressure dependence, 3D petroelastic cubes were computed. The different inputs for the petroelastic model of the different facies are summarized in Appendix C. A cube of Acoustic Impedance (IP), a cube of Shear-wave Impedance (IS), and a cube of P-wave 


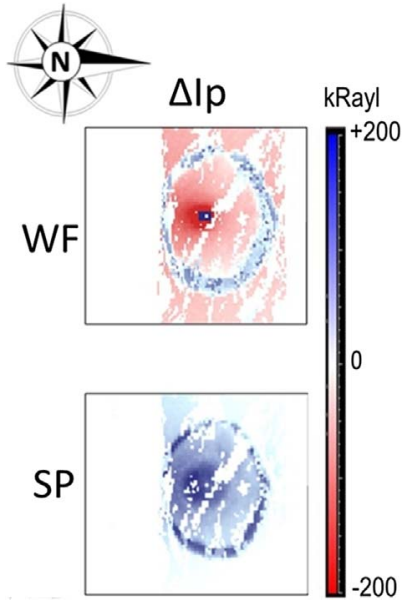

Fig. 11. Horizontal cross-sections halfway up the reservoir for WF (top line) and EOR injection (SP) (bottom line) process of $\mathrm{P}$-wave impedance variation (in $\mathrm{kRayl}$ ).

Velocity (VP) for Baseline and Monitor calendar times are obtained (Biot, 1941; Bourbié et al., 1987; Gassmann, 1951; Rasolofosaon and Zinszner, 2014).

Figure 11 shows the impact of fluid substitution and pressure variation on $I_{\mathrm{P}}$ variations $\left(\Delta I_{\mathrm{P}}\right)$ for both injection strategies (WF and SP). The major seismic impedance variations were due to fluid substitution, whereas $\Delta I_{\mathrm{P}}$ was also sensitive to fluid pressure variation beyond the swept zone but to a lesser extent. As for $\Delta S_{\mathrm{o}}$, the signature of a horizontal spatial correlation of facies, porosity and permeability roughly in the $\mathrm{SE}-\mathrm{NW}$ direction seen in Figure 4 can be observed on the $\Delta I_{\mathrm{P}}$. Furthermore, we can note the absence of impedance variations to the south of the E-W major channel (Fig. 4), denoting a weakly swept zone corresponding to the vanishing $\Delta P$ and $\Delta S_{\mathrm{o}}$ due to the compartmentalization of the reservoir.

\subsection{Synthetic 4D seismic cubes and relevant attributes}

From each triplet of petroelastic cubes $I_{\mathrm{P}}, I_{\mathrm{S}}$, and $V_{\mathrm{P}}$, and for each calendar time, three $\mathrm{P}$-wave seismic cubes were computed by convolution (e.g., Sheriff, 2002) using a high frequency Ricker source (typical $150 \mathrm{~Hz}$ central frequency due to the small thickness of the reservoir). Figure 12a illustrates such a process for the case of normal incidence angle $\left(\theta=0^{\circ}\right)$, with a $3 \mathrm{D}$ view of the difference between the Monitor and the Baseline seismic cubes.

The conversion of the vertical scale from time domain to depth domain is a problem in itself which falls beyond the scope of this work but is a well-known topic (e.g., Bartel et al., 2006; Iversen and Tygel, 2008; Yilmaz, 2001). A very simple way to convert depth to time is to use a $\mathrm{P}$-wave velocity. In our case, this $\mathrm{P}$-wave velocity was computed in the petroelastic modeling step of our workflow. Nevertheless, a critical issue remains and has to be carefully handled in real 4D seismic studies: the time correspondence between all seismic cubes acquired at different calendar times. Between two consecutive seismic acquisitions, the

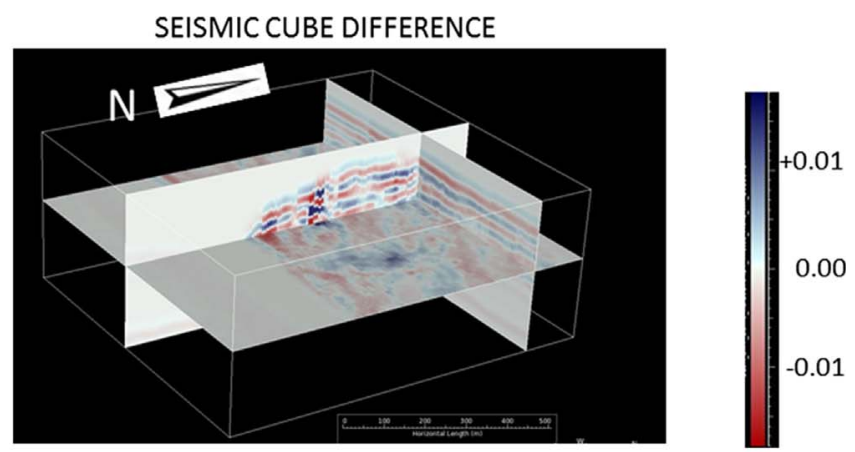

(a)

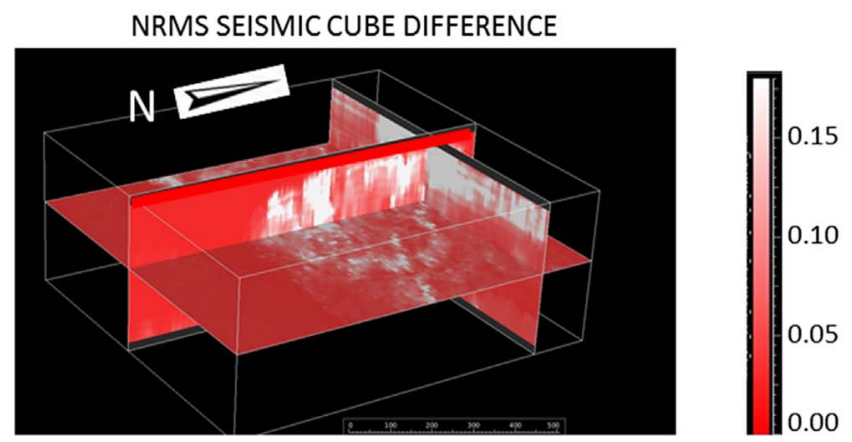

(b)

NRMS HILBERT TRANSF. OF SEISMIC CUBE DIFFERENCE

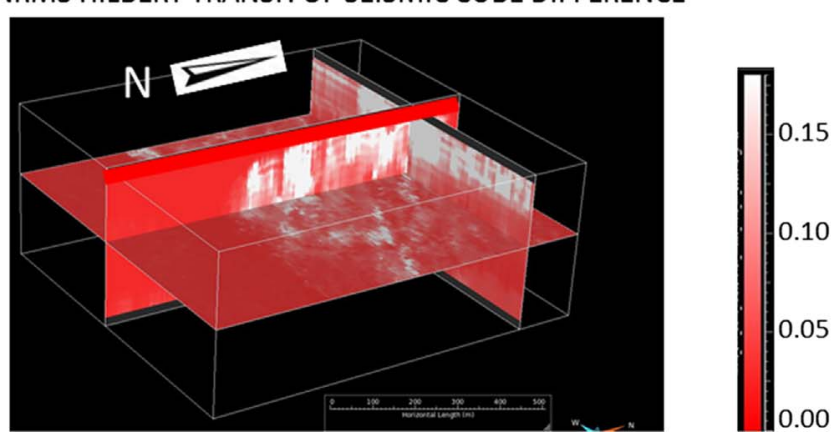

(c)

Fig. 12. WF case - 3D-views (a) of seismic cube difference, (b) of NRMS of seismic cube difference and (c) of NRMS of the Hilbert transform of seismic cube difference between monitor and baseline seismic cubes.

fluid content and the pressure field are different, leading to different $\mathrm{P}$-wave velocities for these two different acquisitions. As a consequence, as illustrated by Figure 13, a horizon at a given depth appears at different travel times for these two different acquisitions, impeding any direct comparison.

This direct comparison can only be done after seismic cubes have been put in time correspondence, as shown in Delépine et al. (2010). In our realistic synthetic case, the time-shift law from Baseline time to Monitor time could be computed easily from the $V_{\mathrm{P}}$ cubes, which allows to put in time correspondence the Monitor cube with the corresponding Baseline cube. All the difference cubes shown on Figure 12 are in the Baseline time. 


\section{BASELINE SEISMIC IMPEDANCE AND SIGNAL (BEFORE INJECTION)}

\section{MONITOR SEISMIC IMPEDANCE AND SIGNAL (AFTER INJECTION)}
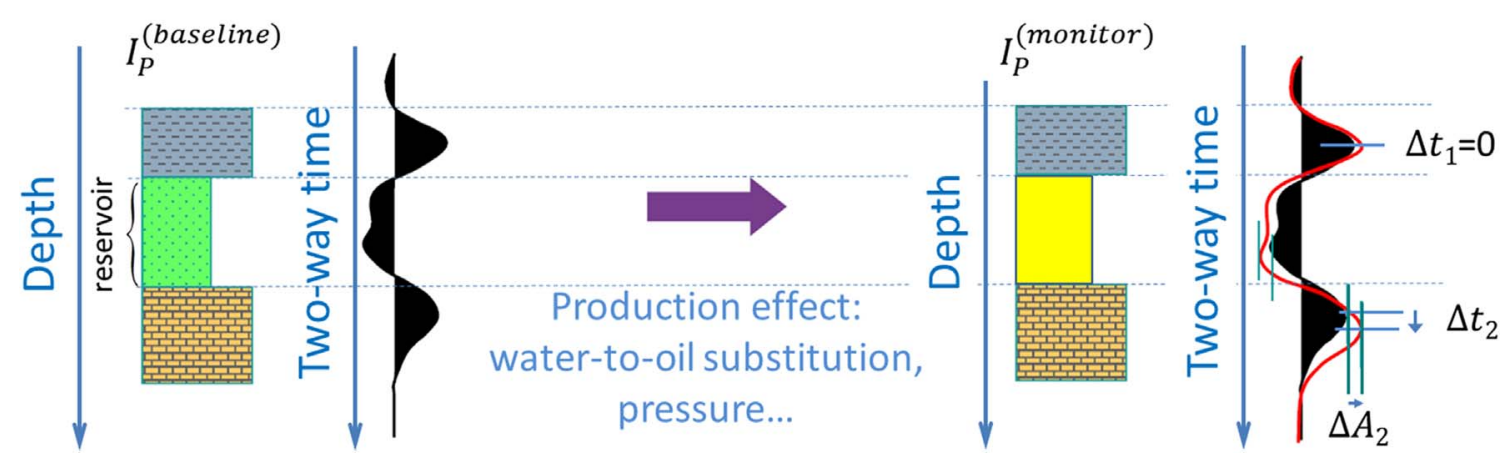

Fig. 13. Principle of time-shift. Left: 3 layers with Ip values expressed in the depth domain induce the seismic signal expressed in the time domain. A fluid substitution is then performed inside the reservoir layer. Right: the horizons are at the same location in the depth domain than on the left, but Ip is different in the reservoir layer, leading to a slightly different seismic signal in the time-domain (timeshift $\Delta t_{2}$ and amplitude variation $\Delta A_{2}$ ).

We can appreciate on Figures 12 and 14 the loss of vertical and horizontal resolution (compared to impedance or saturation variations for instance) due to the limited frequency content of the seismic source. Nevertheless, it is still possible to observe on $4 \mathrm{D}$ monitoring data, highlighting changes in the reservoir, the signature of horizontal spatial correlation of facies, porosity, and permeability which correspond to static characteristics of the reservoir.

At last, Figures $12 \mathrm{~b}$ and $12 \mathrm{c}$ show two of the most relevant attributes of the 4D seismic data, as far as our case study is concerned. These attributes are based on the notion of "Normalized Root Mean Square" (NRMS). In seismics, the NRMS between a first seismic signal (Monitor signal) and a second signal (Baseline signal) is defined by:

$$
\begin{aligned}
\text { NRMS }= & 2 \times \operatorname{RMS}(\text { Monitor }- \text { Baseline }) /[\text { RMS(Monitor }) \\
& +\operatorname{RMS}(\text { Baseline })]
\end{aligned}
$$

where $\operatorname{RMS}(\cdot)$ stands for the "Root Mean Square" of the considered signal. In 4D seismics, the value of NRMS is a well-known quantification of the repeatability of a seismic experiment (e.g., Johnston, 2013). By definition, NRMS can take a numerical value comprised between 0 and 2. In the case of two quite similar seismic signals, the corresponding NRMS value is close to 0 . In contrast, in the case of two quite similar seismic signals but of opposite polarity, the corresponding NRMS value is close to 2 . Figure $12 \mathrm{~b}$ shows the NRMS of the seismic difference (Monitor - Baseline) corresponding to WF scenario, and Figure 12c shows the NRMS of a specific seismic attribute called Hilbert transform (e.g., Sheriff, 2002; Yilmaz, 2001). Hilbert transform, and more exactly the modulus of Hilbert transform of a seismic signal, is a "clean" way, from the physico-mathematical point of view, to quantify the instantaneous amplitude of the seismic wave; the square of this quantity being proportional to the instantaneous

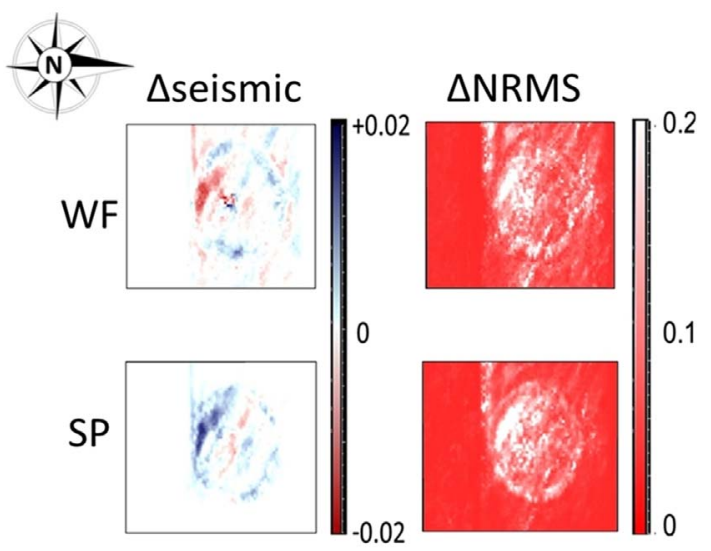

Fig. 14. Horizontal cross-sections halfway up the reservoir for WF (top line) and EOR injection (SP) (bottom line) process on 4D seismic response (1st column), and NRMS of seismic cube difference (2nd column). Note that the loose term " $\Delta$ seimic" stands for the difference between the seismic data in the amplitude domain.

energy transported by the seismic wave. In effect, on both NRMS cubes plotted in Figures 12b and 12c, the NRMS value is quite small in zones not affected by fluid substitution, such as areas in the southern part of the E-W channel or in the overburden. In contrast, NRMS has significant values in areas where seismic properties were affected by injection, either due to fluid substitution or to pressure effect. Note that all these RMS were computed on a time window of fixed width vertically sliding with overlap. The choice of the width of the time window for computing the RMS is important. A too narrow time window can strongly affect the statistical representativeness of the computation. In contrast, a too broad time window contributes to critically decrease the vertical resolution 


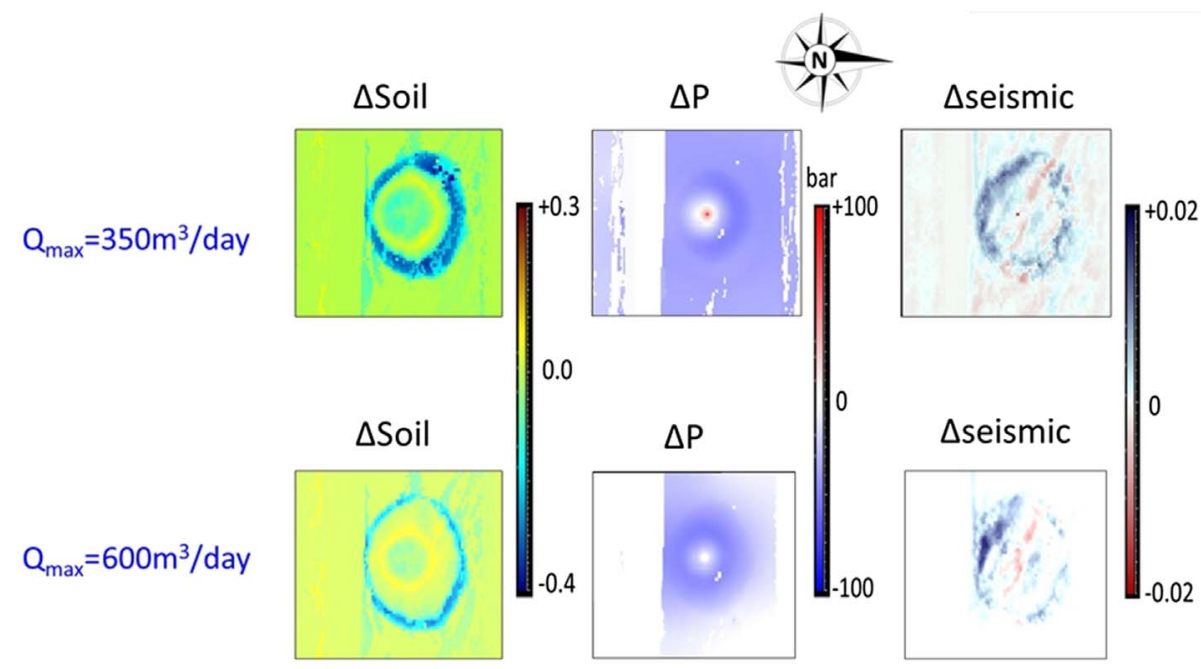

Fig. 15. Influence of the maximum injection rate, namely $350 \mathrm{~m}^{3} /$ day (top line) and $600 \mathrm{~m}^{3} /$ day (bottom line) on the variations of Oil saturation (left column), Fluid pressure (middle column) and Seismic response (right column) between Baseline and Monitor calendar times (SP process). Note that " $\Delta$ seimic" stands for the difference between the seismic data in the amplitude domain.

of the analysis. Here, the width of the time window was close to the period of the seismic source signal.

A horizontal slice of NRMS of the seismic difference cubes (Fig. 12b) corresponding to WF is provided on Figure 14 and can be compared to the same attribute computed for SP scenario. In the case of WF scenario, we can see, beyond the waterfront, the impact of the pressure increase on NRMS. For SP scenario, the NRMS of the seismic difference nicely delineates the swept zone. Indeed, the polymers enhance the viscosity of the injected fluid which induces a slower displacement of the waterfront. The layering effect of water in permeable facies is reduced, so that the waterfront is less scattered horizontally from one layer to the other and appears easier to detect on 4D seismics (less noisy). In this case, the visibility of the waterfront on the real seismic cubes may thus be used to estimate the efficiency of the EOR process.

\section{Impact of the injection rate on the seismic attributes}

For a given EOR strategy, the injection scenario can also have a non-negligible impact on the seismic attributes. To illustrate this, we considered a second SP injection scheme that differs from the previous one by the imposed target maximum fluid injection rate. It was taken equal to $Q_{\max }=350 \mathrm{~m}^{3} \mathrm{~d}^{-1}$ instead of $600 \mathrm{~m}^{3} \mathrm{~d}^{-1}$. The corresponding variations of oil saturation $\Delta S_{\mathrm{o}}$, pressure $\Delta P$ and seismic response between the Monitor and Baseline calendar times are given in Figure 15. The pressure constraints discussed above and detailed in Appendix B, were unchanged. We can see that both $\Delta P$ and $\Delta S_{\mathrm{o}}$ were substantially influenced by this change in $Q_{\max }$. For the low rate case
$\left(Q_{\max }=350 \mathrm{~m}^{3} \mathrm{~d}^{-1}\right)$, high $\Delta P$ values close to the injection well location were observed, while such a behavior did not occur for the high rate case $\left(Q_{\max }=600 \mathrm{~m}^{3} \mathrm{~d}^{-1}\right)$. This is again due to the pressure constraint at the injector. Indeed, at Baseline calendar time, the pressure around the injection well was lower for $Q_{\max }=350 \mathrm{~m}^{3} \mathrm{~d}^{-1}$ than for $Q_{\max }=$ $600 \mathrm{~m}^{3} \mathrm{~d}^{-1}$, but when polymer was injected, the well bottom-hole pressure reached the maximum authorized pressure of 500 bar whatever the injection rate scenario (see Fig. B2 in Appendix B). That is the reason why $\Delta P$ values were higher for the low rate case than for the high rate case. As far as variation of oil saturation is concerned, a low injection rate led to a better oil sweep (light blue to blue zones) in the area swept between Baseline and Monitor calendar times. The area swept with water before Baseline calendar time is also better swept using $Q_{\max }=350 \mathrm{~m}^{3} \mathrm{~d}^{-1}$ and the layering effect observed at the Baseline date is lower than the one observed for $Q_{\max }=600 \mathrm{~m}^{3} \mathrm{~d}^{-1}$. This behavior is not general and depends on the reservoir properties and injectionproduction strategy and control. If we consider, for this period, the effective water injection rate for the two injection scenarios (Fig. B2 in Appendix B), the scenario $Q_{\max }=350 \mathrm{~m}^{3} \mathrm{~d}^{-1}$ was the one for which the larger amount of fluid was injected, inducing a better oil recovery. As a consequence, the polymer has a lower and more diffusive impact, which induces a lower quantity of remobilized oil and a finer and less continuous yellow ring than for $Q_{\max }=600 \mathrm{~m}^{3} \mathrm{~d}^{-1}$.

On Figure 15, we can see that the seismic signature was sensitive to this peculiar behavior and, even if the scenario $Q_{\max }=350 \mathrm{~m}^{3} \mathrm{~d}^{-1}$ led to a better sweep efficiency between Baseline and Monitor calendar times, the 4D seismic data seemed to be more noisy. In this case, it may thus be more difficult to interpret these data in terms of efficiency of 
the process, what emphasizes the importance of estimating the potential of $4 \mathrm{D}$ seismics prior to any acquisition.

\section{Discussion}

First of all, our integrated simulation approach helps to rank the impact of different parameters and effects (reservoir heterogeneity, fluid substitution, and pressure effects) and their unintuitive combined effects on seismic response. Regarding the contribution of time-lapse seismics to monitor chemical EOR, our integrated experiment once again clearly illustrates the evolution of $4 \mathrm{D}$ seismics. More precisely, in the 1990s the technique was considered as a sophisticated geophysical interpretation tool and was used by a handful of specialists. Now the technique is commonly used and helps in practical reservoir management. First of all, we emphasize the necessity of clean and appropriate processing of the data, as recommended in classical references on the topic (for instance Johnston, 2013). All these requirements were met in our study since we were dealing with direct problem simulation in perfect seismic acquisition and processing conditions. We are perfectly aware of the importance of correcting, or compensating for the variations in acquisition (e.g., overburden issues, seasonal effect or more general external condition variations not due to the subsurface exploitation, source/receiver positioning...), processing parameters, or the background noise as detailed in the last reference.

No noise equivalent to acquisition noise, background noise..., contributing to non-repeatability of the seismic acquisition, was numerically added to our synthetics. However noise is "intrinsically" present in the synthetics due to the randomness of the media induced by the geostatistical simulation characterized by Table A1. This also induces randomness of fluid and pressure distributions. All of these factors add noise to the synthetic data. Variations of both fluid saturation and fluid pressure due to reservoir exploitation are illustrated by Figure 9. In each of the two considered cases (Water flooding [WF] and EOR injection [SP]), one can roughly separate two spatial zones. A first zone bounded by a pseudo elliptical frontier plotted in blue on the figure where variations of both fluid saturation and fluid pressure are observed. We coarsely call this region the "swept zone". Outside this zone, even far from the boundary of the swept zone, mainly variation of fluid pressure is observed. The detection of the frontier between these two zones by $4 \mathrm{D}$ seismics is central in the present paper. According to Figure 14 the maximum value of the 4D NRMS due to $4 \mathrm{D}$ effect in the "swept zone" is around $20 \%$ both for Water Flood (WF) and EOR injection (SP). This quantity is called by some authors (e.g., Johnston, 2013) the detectability, that is to say the magnitude of the seismic response to production changes in the swept zone. Furthermore, Lumley et al. (1997) detailed the reservoir, fluid and seismic properties that affect the detectability factor and influence the chance of success of $4 \mathrm{D}$ seismics. In our case the observed detectability value is consistent with typical values of 4D NRMS for offshore survey reported in the literature, varying from $10 \%$ to
$25 \%$ (e.g., Kragh and Christie, 2002). Note exceptional values as high as $35 \%$ in Draugen field measured by Koster et al. (2000) for water replacing oil. In contrast the 4D NRMS noise away from the swept zone is substantially smaller than the NRMS in the swept zone. A stronger 4D NRMS noise outside the swept zone is observed in the WF case (roughly $8 \%$ in average) than in the SP case (roughly $5 \%$ in average), both spatial dependent. In both cases, the 4D NRMS noise is clearly weaker than the measured detectability of the swept zone $20 \%$ except in specific directions, roughly $\mathrm{E}-\mathrm{W}$ direction, and only in the case of WF as illustrated by Figure 14. All these ensure the detectability of the boundary of the swept zone.

A more complete study of the effect of "extrinsically" added noise on the non-repeatability of seismics and its implication on 4D interpretation, such as those of Houck (2010), will be part of further studies.

With the proviso related to the absence of "extrinsic" noise, we demonstrated that $4 \mathrm{D}$ seismics can contribute to the assessment of chemical EOR efficiency. First, as in the case of other types of subsurface exploitation, one of the major contributions of the technique is to enable the identification of water front around the swept zone and also the identification of unswept zones and flow barriers. The example of the E-W channel to the south is convincing, with no substantial variations in fluid pressure and in fluid saturation, inducing negligible seismic difference response to the south of the channel, as illustrated by Figure 11. This information is of value to understand the reservoir flow behavior and the hydraulic connectivity, and can assist in improving reservoir management. However, due to the multiplicity of the factors and their combined effects, 4D seismics may fail to detect chemical impacts on some geological reservoirs or for some injection strategies. That is the reason why such kind of integrated workflow is very valuable to help to decide whether to monitor a field or not, and to design the most relevant monitoring strategy depending on the objective (fluid saturation quantification, fluid movement estimation, connectivity...). Frequently repeating seismic acquisition on few specific 2D lines may also be chosen thanks to such feasibility study. As proposed by Hatchell (2015) for deep-water fields, a lower cost solution for $4 \mathrm{D}$ monitoring could be to reduce monitored field surface and to shoot small target subsets taking benefit of the scalability of OBN solution. This would enable frequent monitoring of specific areas of interest which could be chosen thanks to this kind of integrated workflow as well.

These conclusions on the contribution of $4 \mathrm{D}$ seismics to the present work may appear rather less impressive compared to what has been achieved in other contexts with this technique, for instance on Sleipner field (North Sea) for the geological storage of carbon dioxide $\left(\mathrm{CO}_{2}\right)$ as described in Dubos-Sallée and Rasolofosaon (2010). In the present study, except for the high data quality, we faced multiple unfavorable conditions: (i) the reservoir rock was roughly less compliant in average, (ii) the saturating fluids were of comparable compressibility, (iii) fluid pressure effect could not be neglected, and (iv) the reservoir exhibited rather strong facies and permeability distribution heterogeneity. 
Despite this, and with the proviso of the relevant seismic processing and choice of attributes, important geometrical details of the swept and unswept zones were obtained. To go beyond this mere geometrical approach, a first step would be to use seismic cubes at zero-offset but also at small-offset and at large-offset, or even both P-wave data and S-wave data, at least in order to discriminate between pressure effect and fluid substitution effect (e.g., Landrø, 2001). An even further step would be to use full waveform modeling instead of 1D-convolution, with the resulting further complication of the inversion and interpretation of the data (Bourgeois et al., 2004). However, such a more complete modeling is more realistic and can contain more information on both the $3 \mathrm{D}$ geometry and the elastic properties of the reservoir.

For real field cases, several reservoir models may reproduce the available data (logs, production data) but provide various production forecasts for a given development plan. If available, this uncertainty should be taken into account in the proposed workflow and seismic data should also be used to constrain the model through history-matching.

Finally, our workflow can be of interest for communication between geophysicists and reservoir engineers involved in the same operational team and could facilitate a virtuous circle between them. With this workflow, reservoir engineers can test the optimal range of production conditions leading to the best oil recovery. Using this information, geophysicists can then infer, and share with reservoir engineers, in which production conditions quantitative $4 \mathrm{D}$ seismic interpretation would be optimal. Then reservoir engineers have all necessary information to determine the best production strategy.

\section{Conclusion}

This paper investigates the ability of $4 \mathrm{D}$ seismics to capture the chemical impacts during a tertiary oil recovery phase and to identify characteristic features that can be related to the success of the EOR strategy. Seismic cubes were computed on a realistic case based on an outcrop analog of turbiditic reservoirs, considering two production strategies: the first one consists in a surfactant-polymer injection, and the second one in a classical waterflooding. The computation of the seismic responses was performed based on a workflow that spans from the geological description to seismic monitoring simulation and seismic attributes analysis, through geological and reservoir modeling, flow simulation, and rock physics modeling. The surfactant-polymer injection strategy induces changes in the dynamic behavior of the reservoir that are visible on the seismic attributes. Despite the loss of resolution, it may also lead to characteristic features on the seismic response. In particular, a clear delineation of the waterfront compared to classical water flooding can appear. In this case, the real seismic cubes may be used to estimate the efficiency of the process. In other cases, the seismic response may however be too noisy to justify the acquisition process. This underlines the necessity to test the ability of $4 \mathrm{D}$ seismics to detect a chemical impact before monitoring a field.
With the workflow considered here, each expert of the different fields can benefit from the availability of a complete set of well-controlled data of various types to test and improve his own tools. In contrast, the non-experts can easily and quickly benefit from "hands-on" experiments to understand the involved phenomena. As a direct consequence, it is easy to understand that any output of our workflow can be used for educational purpose towards a well-documented full case study. The new digital tools and techniques provide a new relation to training and can be a very powerful way to increase the learning capacity of students or professionals. These even allow to better train them directly in the field and in the laboratory (e.g., Joseph, 2017; Marçal et al., 2017).

Regarding future work, the completeness of the workflow and the manageability of the modest-size model open the door to several extensions of the present work. A short-term future work could be the study of alternate production strategies and well locations on this synthetic case. Complementary tests have already been performed in such direction, but only limited illustrative examples have been reported in the present paper for brevity. A detailed description of complementary results can be found in Zarate-Rada (2016). The proposed workflow can also be directly applied to geological reservoirs all over the world. There is no methodological barrier that would avoid our approach to be adapted even to quite different geological contexts and fields.

Acknowledgments. We gratefully acknowledge IFPEN and IFP School for permission to present this contribution.

\section{References}

Adams E.W., Grélaud C., Pal M., Csoma A.E., Al Ja'aidi O.S., Al Hinai R. (2011) Improving reservoir models of Cretaceous carbonates with digital outcrop modelling (Jabal Madmar, Oman): Static modelling and simulating clinoforms, Petrol. Geosci. 17, 3, 309-322. doi: 10.1144/1354-079310-031.

Arbués P., Mellere D., Falivene O., Fernández O., Muñoz J.A., Marzo M., De Gibert J.M. (2007) Context and architecture of the Ainsa-1-quarry channel complex, Spain, in: Nielsen T.H., Shew R.D., Steffens G.S., Studlick J.R.J. (eds), Atlas of DeepWater Outcrops. AAPG Studies in Geology 56, Chapter 147, American Association of Petroleum Geologists, Tulsa, OK.

Armitage D.A., Stright L. (2010) Modeling and interpreting the seismic-reflection expression of sandstone in an ancient masstransport deposit dominated deep-water slope environment, Mar. Pet. Geol. 27, 1, 1-12. doi: 10.1016/j.marpetgeo.2009. 08.013.

Bakke K., Kane I.A., Martinsen O.J., Petersen S.A., Johansen T.A., Hustoft S., Jacobsen F.H., Groth A. (2013) Seismic modeling in the analysis of deep-water sandstone termination styles, AAPG Bull. 97, 9, 1395-1419. doi: 10.1306/ 03041312069.

Bartel D.C., Busby M., Nealon J., Zaske J. (2006) Time to depth conversion and uncertainty assessment using average velocity modeling, in: 66th SEG Annual International Meeting, New Orleans, Louisiana, USA, SEG Expanded Abstracts, pp. 21662170. doi: 10.1190/1.2369965. 
Batzle M., Wang Z. (1992) Seismic properties of pore fluids, Geophysics 57, 11, 1396-1408. doi: 10.1190/1.1443207.

Bear J. (1972) Dynamics of fluids in porous media, Elsevier, New-York.

Beyer R.T. (1965) Nonlinear acoustics, Phys. Acoust. 2, Part B, 231-264. doi: 10.1016/B978-0-12-395662-0.50014-X.

Biot M.A. (1941) General theory of three-dimensional consolidation, J. Appl. Phys. 12, 155-164. doi: 10.1063/1. 1712886.

Borozdina O., Mamaghani M., Barsalou R., Lantoine M., Pain A. (2019) Coreflood Model Optimization Workflow for ASP Pilot Design Risk Analysis, in: SPE Middle East Oil and Gas Show and Conference, 18-21 March, Manama, Bahrain, Society of Petroleum Engineers. doi: 10.2118/194855-MS.

Bourbiaux B., Fourno A., Nguyen Q.-L., Norrant F., Robin M., Rosenberg E. (2015) Experimental and numerical assessment of chemical enhanced oil recovery in oil-wet naturally fractured reservoirs, SPE J. 21, 3, 706-719. doi: 10.2118/169140-PA.

Bourbié T., Coussy O., Zinszner B. (1987) Acoustics of porous media, Editions Technip, Paris.

Bourgeois A., Joseph P., Lecomte J.-C. (2004) Three-dimensional full wave seismic modelling versus one-dimensional convolution: The seismic appearance of the Grès d'Annot turbidite system, in: Joseph P., Lomas S.A. (eds), Deep-water sedimentation in the Alpine Basin of SE France: New perspectives in the Grès d'Annot and related systems. Special Publications 221, Geological Society, London, UK, pp. 401-417.

Calvert R. (2005) Insights and methods for $4 D$ reservoir monitoring and characterization. Distinguished Instructor Series $n^{\circ} 8$, SEG and EAGE, Tulsa, OK/Houten, The Netherlands. doi: 10.1190/1.9781560801696.

Cockin A.P., Malcolm L.T., McGuire P.L., Giordano R.M., Sitz C.D. (2000) Analysis of a single-well chemical tracer test to measure the residual oil saturation to a hydrocarbon miscible gas flood at Prudhoe Bay, SPE Res. Evalu. Eng. 3, 6, 544-551. doi: 10.2118/68051-PA.

Cossé R. (1993) Basics of reservoir engineering, Éditions Technip, Paris.

Deans H.A. (1971) Method of determining fluid saturations in reservoirs. US Patent No. 3,623,842.

Deans H.A., Carlisle C.T. (2007) The single-well chemical tracer test - a method for measuring reservoir fluid saturations in situ, in: Holstein E.D. (ed), SPE Petroleum Engineering Handbook, Reservoir Engineering and Petrophysics, Vol. V, Society of Petroleum Engineers, pp. 615-649.

Delamaide E., Zaitoun A., Gérard R., Tabary R. (2014) Pelican lake field: First successful application of polymer flooding in a heavy-oil reservoir, SPE Res. Evalu. Eng. 17, 3, 340-354. doi: 10.2118/165234-PA.

Delaplace P., Delamaide E., Roggero F., Renard G. (2013) History matching of a successful polymer flood pilot in the Pelican Lake heavy oil field (Canada), in: SPE Annual Technical Conference and Exhibition, 30 September-2 October, New Orleans, LA, USA. doi: 10.2118/166256-MS.

Delépine N., Labat K., Clochard V., Ricarte P., Le Bras C. (2010) 4D Joint pre-stack seismic stratigraphic inversion of the Sleipner- $\mathrm{CO}_{2}$ case, in: 72nd EAGE Conference and Exhibition Incorporating SPE EUROPEC 2010, Barcelona, Spain, Extended Abstract, K009. doi: 10.3997/2214-4609.201400921.

Demin W., Zhenhua Z., Jiecheng C., Jingchun Y., Shutang G., Li L. (1997) Pilot test of alkaline surfactant polymer flooding in Daqing oil field, SPE Res. Eng. 12, 4, 229-233. doi: $10.2118 / 36748-P A$.
Doherty P.D., Soreghan G.S., Castagna J.P. (2002) Outcrop-based reservoir characterization: A composite phylloid-algal mound, western Orogrande basin (New Mexico), AAPG Bull. 86, 5, 779 795. doi: 10.1306/61EEDB98-173E-11D7-8645000102C1865D.

Doligez B., Beucher H., Geffroy F., Eschard R. (1999) Integrated reservoir characterization: improvement in heterogeneous stochastic modeling by integration of additional external constraints, in: Schatzinger R., Jordan J. (eds), Reservoir Characterization - Recent Advances, AAPG Memoir, Vol. 71, American Association of Petroleum Geologists, Tulsa, OK, pp. 333-342.

Douarche F., Da Veiga S., Feraille M., Enchéry G., Touzani S., Barsalou S. (2014) Sensitivity analysis and optimization of surfactant-polymer flooding under uncertainties, Oil Gas Sci. Technol. - Rev. IFP Energies nouvelles 69, 4, 603-617. doi: $10.2516 /$ ogst $/ 2013166$.

Douarche F., Rousseau D., Bazin B., Tabary R., Moreau P., Morvan M. (2012) Modeling Chemical EOR Processes: Some illustrations from Lab to Reservoir Scale, Oil Gas Sci. Technol. - Rev. IFP Energies nouvelles 67, 6, 983-998. doi: $10.2516 /$ ogst $/ 2012059$.

Dubos-Sallée N., Rasolofosaon P.N.J. (2010) Data-driven quantitative analysis of the $\mathrm{CO}_{2}$ plume extension from $4 \mathrm{D}$ seismic monitoring in Sleipner, in: 72nd EAGE Conference and Exhibition incorporating SPE EUROPEC 2010, Barcelona, Spain, Extended Abstract, K010. doi: 10.3997/2214-4609. 201400922.

Falivene O., Arbués P., Gardiner A., Pickup G., Muñoz J.A., Caberra L. (2006a) Best practice stochastic facies modeling from a channel-fill turbidite sandstone analog (the Quarry outcrop, Eocene Ainsa Basin, northeast Spain), AAPG Bull. 90, 7, 1003-1029. doi: 10.1306/02070605112.

Falivene O., Arbués P., Howell J., Muñoz J.A., Fernández O., Marzo M. (2006b) Hierarchical geocellular facies modelling of a turbidite reservoir analogue from the Eocene of the Ainsa Basin, NE Spain, Mar. Pet. Geol. 23, 6, 679-701. doi: 10.1016/j.marpetgeo.2006.05.004.

Falivene O., Arbués P., Ledo J., Benjumea B., Muñoz J.A., Fernández O., Martínez S. (2010) Synthetic seismic models from outcrop-derived reservoir-scale three-dimensional facies models: The Eocene Ainsa turbidite system (southern Pyrenees), AAPG Bull. 94, 3, 317-343. doi: 10.1306/ 08030908157.

Galli A., Beucher H., Le Loc'h G., Doligez B., Heresim Group. (1994) The Pros and Cons of the truncated Gaussian method, in: Armstrong M., Dowd P.A. (eds), Geostatistical Simulations, Quantitative Geology and Geostatistics, Vol. 7, Springer, Dordrecht, pp. 217-233. doi: 10.1007/978-94-015-8267-4 18.

Gasparrini M., Lopez-Cilla I., Blazquez-Fernandez S., Rosāes I., Lerat O., Martin-Chivilet J., Doligez B. (2016) A multidisciplinary modeling approach to assess facies-dolomitizationporosity interdependence in a lower cretaceous platform (Northern Spain), in: Advances in Characterization and Modeling of Complex Carbonate Reservoirs - In Memory of Eric Mountjoy, SEPM (Society for Sedimentary Geology), Broken Arrow, OK. doi: 10.2110/sepmsp.109.07.

Gassmann F. (1951) Über die elastizität poröser medien, Vierteljahrsschrift der Naturforschenden Geselschaft in Zürich 96, 1-23. English translation available from: http:// sepwww.stanford.edu/sep/berryman/PS/gassmann.pdf.

Green D.W., Willhite G.P. (1998) Enhanced oil recovery. SPE Textbook Series Vol. 6, SPE, TX, USA. 
Hatchell P. (2015) Experience with time-lapse monitoring using ocean bottom nodes in deepwater fields. EAGE E-lecture Series, https://www.youtube.com/watch?v=1jm70tZ8liE.

Helgerud M.B., Miller A.C., Johnston D.H., Udoh M.S., Jardine B.G., Harris C., Aubuchon N. (2011) 4D in the deepwater Gulf of Mexico: Hoover, Madison, and Marshall fields, Lead. Edge 30, 9, 1008-1018.

Holgate N.E., Hampson G.J., Jackson C.A.-L., Petersen S.A. (2014) Constraining uncertainty in interpretation of seismically imaged clinoforms in deltaic reservoir, Troll field, Norwegian North Sea: Insights from forward seismic models of outcrop analogs, AAPG Bull. 98, 12, 2629-2663. doi: $10.1306 / 05281413152$.

Hou J., Liu Z., Zhang S., Yue X., Yang J. (2005) The role of viscoelasticity of alkali/surfactant/polymer solutions in enhanced oil recovery, J. Pet. Sci. Eng. 47, 3-4, 219-235. doi: 10.1016/j.petrol.2005.04.001.

Houck R.T. (2010) Value of geophysical information for reservoir management, Meth. Appl. Res. Geophys. 15, 29.

Houpeurt A. (1975) Éléments de mécanique des fluides dans les milieux poreux, Editions Technip, Paris.

Iske A., Randen T. (2006) Mathematical methods and modelling in hydrocarbon exploration and production, Springer Science \& Business Media, Berlin, Germany.

Iversen E., Tygel M. (2008) Image-ray tracing for joint 3D seismic velocity estimation and time-to-depth conversion, Geophysics 73, 3, S99-S114. doi: 10.1190/1.2907736.

Janson X., Fomel S. (2011) 3-D forward model of an outcrop-based geocellular model, in: Martinsen O.J., Pulham A.J., Haughton P.D.W., Sullivan M.D. (eds), Outcrops Revitalized, Society for Sedimentary Geology, pp. 87-106. doi: 10.2110/sepmcsp.10.087.

Jardin A., Joseph P., Koochak Zadeh M., Lerat O. (2010) Quantitative interpretation of multi-dimensional seismic models of turbidite channels from the Ainsa-1 quarry, Spain, 72nd EAGE Conference \& Exhibition, Barcelona, Spain. Expanded Abstract, P065. doi: 10.3997/2214-4609.201401078.

Johnston D.H. (2013) Practical applications of time-lapse seismic data. Distinguished Instructor Series $\mathrm{n}^{\circ} 16$, SEG, Tulsa, OK. doi: 10.1190/1.9781560803126.

Joseph P. (2017) Use of virtual outcrops for mobile learning during field trips and practical case studies in geosciences, in: Presented at the Workshop WS17 "Value of Virtual outcrops in Geosciences", 79th EAGE Conference and Exhibition, 16 June, Paris, France.

Koster K., Gabriels P., Hartung M., Verbeek J., Deinum G., Staples R. (2000) Time-lapse seismic surveys in the North Sea and their business impact, Lead. Edge 19, 3, 286-293.

Kragh E.D., Christie P. (2002) Seismic repeatability, normalized rms, and predictability, Lead. Edge 21, 7, 640-647.

Labat K., Delépine N., Clochard V., Ricarte P. (2012) 4D joint stratigraphic inversion of prestack seismic data: Application to the $\mathrm{CO}_{2}$ storage reservoir (Utsira sand formation) at Sleipner site, Oil Gas Sci. Technol. - Rev. IFP Energies nouvelles 67, 2, 329-340. doi: 10.2516/ogst/2012006.

Lake L.W., Johns R.T., Rossen W.R., Pope G.A. (2014) Fundamentals of enhanced oil recovery, Society of Petroleum Engineers.

Landrø M. (2001) Discrimination between pressure and fluid saturation changes from time-lapse seismic data, Geophysics 66, 3, 836-844. doi: 10.1190/1.1444973.

Landro M., Solheim O.A., Hilde E., Ekren B.O., Stronen L.K. (1999) The Gullfaks 4D seismic study, Petrol. Geosci. 5, 3, 213-226.
Le Ravalec M., Tillier E., Da Veiga S., Enchéry G., Gervais V. (2012) Advanced integrated workflows for incorporating both production and $4 \mathrm{D}$ seismic-related data into reservoir models, Oil Gas Sci. Technol. - Rev. IFP Energies nouvelles 67, 2, 207-220. doi: 10.2516/ogst/2011159.

Lerat O., Nivlet P., Doligez B., Lucet N., Roggero F., Berthet P., Lefeuvre F., Vittori J. (2007) Construction of a stochastic geological model constrained by high resolution 3D seismic data - application to the Girassol field, offshore Angola, in: Presented at the SPE Annual Technical Conference and Exhibition, 11-14 November, Anaheim, CA, USA, pp. 11-14. doi: 10.2118/110422-MS.

Leray S., Douarche F., Tabary R., Peysson Y., Moreau P., Preux C. (2016) Multi-objective assisted inversion of chemical EOR corefloods for improving the predictive capacity of numerical models, J. Pet. Sci. Eng. 146, 1101-1115. doi: 10.1016/j.petrol.2016.08.015.

Lumley D.E., Behrens R.A., Wang Z. (1997) Assessing the technical risk of a 4-D seismic project, Lead. Edge 16, 9, 12871292.

Lumley D.E., Nunns A.G., Delorme G., Adeogba A.A., Bee M.F. (1999) Meren Field, Nigeria: A 4D seismic case study, in: $S E G$ Technical Program Expanded Abstracts 1999, Society of Exploration Geophysicists, Tulsa, OK, pp. 1628-1631.

Lyons W.C., Plisga G.J. (2011) Standard handbook of petroleum and natural gas engineering, 3rd edn., Gulf Professional Publishing, Burlington, MA.

Manrique E.J., Thomas C.P., Ravikiran R., Izadi Kamouei M., Lantz M., Romero J.L., Alvarado V. (2010) EOR: current status and opportunities, in: Presented at the SPE Improved Oil Recovery Symposium, 24-28 April, Tulsa, OK, USA. doi: 10.2118/130113-MS.

Marçal E., de Castro Andrade R.M., Viana W. (2017) Mobile Learning em aulas de campo: um estudo de caso em Geologia (Mobile Learning in field trips: a case study in Geology), RIED: Rev. Iberoam. Educ. Distancia 20, 2, 315-336. In Portugese.

Massonnat G.J., Rolando J.-P., Danquigny C. (2017) The ALBION project: An observatory in the heart of a carbonate reservoir, Abu Dhabi International Petroleum Exhibition \& Conference, 13-16 November, Abu Dhabi, UAE. Society of Petroleum Engineers. doi: 10.2118/188539-MS.

Mavko G., Mukerji T., Dvorkin J. (1998) The rock physics handbook, Cambridge Univ. Press, Cambridge, UK.

Muskat M., Wyckoff R.D. (1937) Flow of homogeneous fluids through porous media, J.W. Edwards, Ann Arbor, MI.

Onuwaje A., Adejonwo A., Al-Mandhary I., Detomo R. Jr, Effiom O., Gouveia W., Kremers N., Legius E., MacLellan A., Mcclenaghan R., Quadt E. (2009) The Bonga 4D - Shell Nigeria's first deepwater time lapse monitor, in: 71st EAGE Conference and Exhibition incorporating SPE EUROPEC 2009.

OpenFlow Softwares (2015/2016) Version 2015/2016, IFPEN/ Beicip-Franlab, Rueil-Malmaison, France. http://www. beicip.com/openflow-suite.

Peaceman D.W. (1983) Interpretation of well-block pressures in numerical reservoir simulation with nonsquare grid blocks and anisotropic permeability, SPE J. 23, 3, 531-543. doi: 10.2118/ 10528-PA.

Pickering K.T., Corregidor J., Clark J.D. (2015) Architecture and stacking patterns of lower-slope and proximal basin-floor channelised submarine fans, Middle Eocene Ainsa, Earth Sci. Rev. 144, 47-81. doi: 10.1016/j.earscirev.2014.11.017. 
Pringle J.K., Howell J.A., Hodgetts D., Westerman A.R., Hodgson D.M. (2006) Virtual outcrop models of petroleum reservoir analogues: A review of the current state-of-the-art, First Break 24, 3, 33-42. doi: 10.3997/1365-2397.2006005.

Rasolofosaon P.N.J., Zinszner B. (2009) Poroelastic equations closely examined by ultrasonic experiments in rocks, in Ling H.I., Smyth A., Betti R. (eds), Poromechanics IV, Proceedings of the Fourth Biot Conference on Poromechanics, DEStech Publications Inc., Lancaster, pp. 661-666.

Rasolofosaon P.N.J., Zinszner B. (2012) Experimental verification of the petroelastic model in the laboratory - Fluid substitution and pressure effects, Oil Gas Sci. Technol. - Rev. IFP Energies nouvelles 67, 2, 303-318. doi: 10.2516/ogst/ 2011167.

Rasolofosaon P.N.J., Zinszner B. (2014) Petroacoustics - a tool for applied seismics, EDP Sciences, Les Ulis, France. http://books. ifpenergiesnouvelles.fr/ebooks/petroacoustics/index.htm.

Roggero F., Lerat O., Ding D.Y., Berthet P., Bordenave C., Lefeuvre F., Perfetti P. (2012) History matching of production and 4D seismic data: Application to the Girassol field, offshore Angola, Oil Gas Sci. Technol. - Rev. IFP Energies nouvelles 67, 2, 237-262. doi: 10.2516/ogst/2011148.

Schmitz J., Deschamps R., Joseph P., Lerat O., Doligez B., Jardin A. (2014) From 3D photogrammetric outcrop models to reservoir models: An integrated modelling workflow, in: Presented at the Vertical Geology Conference, 5-7 February, Lausanne, Switzerland.

Schwab A.M., Cronin B.T., Ferreira H. (2007) Seismic expression of channel outcrops: Offset stacked versus amalgamated channel systems, Mar. Pet. Geol. 24, 6-9, 504-514. doi: 10.1016/j.marpetgeo.2006.10.009.
Sheriff R.E. (2002) Encyclopedic dictionary of applied geophysics, SEG, Tulsa, OK. doi: 10.1190/1.9781560802969.

Stright L., Stewart J., Campion K., Graham S. (2014) Geologic and seismic modeling of a coarse-grained deep-water channel reservoir analog (Black's Beach, La Jolla, California), AAPG Bull. 98, 4, 695-728. doi: 10.1306/09121312211.

Tillier E., Le Ravalec M., Da Veiga S. (2012) Simultaneous inversion of production data and seismic attributes: Application to a synthetic SAGD produced field case, Oil Gas Sci. Technol. - Rev. IFP Energies nouvelles 67, 2, 289-301. doi: $10.2516 /$ ogst $/ 2012004$.

Vargo J., Turner J., Bob V., Pitts M.J., Wyatt K., Surkalo H., Patterson D. (2000) Alkaline-surfactant-polymer flooding of the Cambridge Minnelusa Field, SPE Res. Evalu. Eng. 3, 6, 552-558. doi: 10.2118/68285-PA.

Yilmaz Ö. (2001) Seismic data analysis: Processing, inversion, and interpretation of seismic data, SEG, Tulsa, OK. doi: 10.1190/1.9781560801580.

Zarate-Rada J. (2016) Chemical enhanced oil recovery modelling, MS Memoir in Développement et Exploitation des Gisements, IFP School, Rueil-Malmaison, France. Available from: https:// hal-ifp.archives-ouvertes.fr/hal-01779611/document.

Zerpa L.E., Queipo N.V., Pintos S., Salager J.L. (2005) An optimization methodology of alkaline-surfactant-polymer flooding processes using field scale numerical simulation and multiple surrogates, J. Pet. Sci. Eng. 47, 3-4, 197-208. doi: 10.1016/j.petrol.2005.03.002.

Zinszner B., Pellerin F.M. (2007) A geoscientist's guide to petrophysics, Editions Technip, Paris. 


\section{Appendix A}

\section{Geological and reservoir modeling characteristics}

\section{Elements for facies modeling}

Four vertical logs taken from the outcrop were used to model facies distribution, extracted from sedimentological sections 5, 8, 12, and 14 (pseudo-well locations displayed in Fig. A1).

As outcrop thickness layers $(\sim 0.15 \mathrm{~m})$ are smaller than vertical mesh size discretization $(\sim 0.5 \mathrm{~m})$, an upscaling step is used to import facies logs to the Ainsa reservoir grid (Fig. A2).

In addition, facies proportions are deduced from four vertical sedimentological sections selected across the outcrop and also used to build the facies model obtained by Jardin et al. (2010). To better constrain a new facies model, four synthetic vertical logs (Fig. A3) were extracted from the facies model simulated in Jardin et al. (2010). The approaches considered for simulation are the Truncated Gaussian method (Doligez et al., 1999, Galli et al., 1994) for units $\mathrm{C} 1$ and $\mathrm{C} 2.2$ and the sequential indicator simulation for units C2.1 and C3 (Fig. A1b). These geostatistical approaches have already been applied successfully in many depositional settings, including deep offshore settings (Jardin et al., 2010, Lerat et al., 2007).

\section{Associated petrophysical parameters}

Petrophysical properties are generated using a truncated Gaussian distribution for porosity and a truncated lognormal distribution for permeability. The characteristics

a)

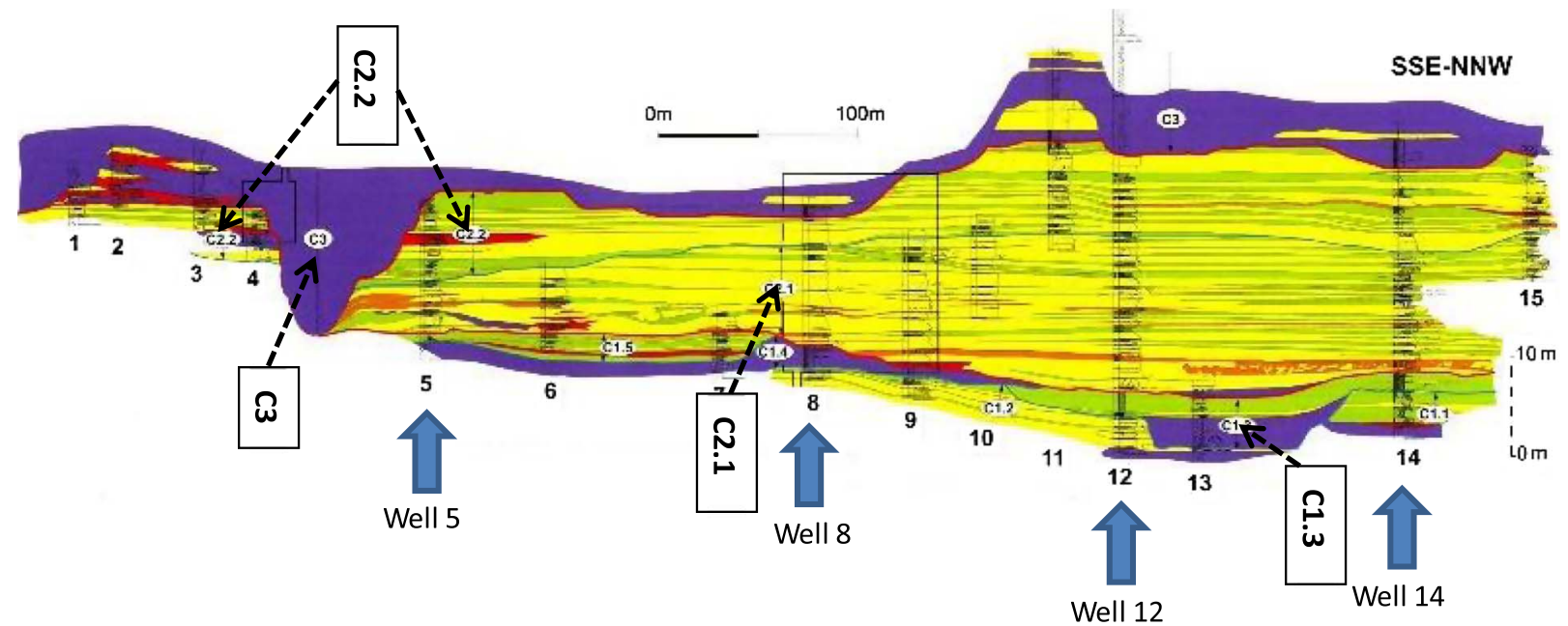

b)

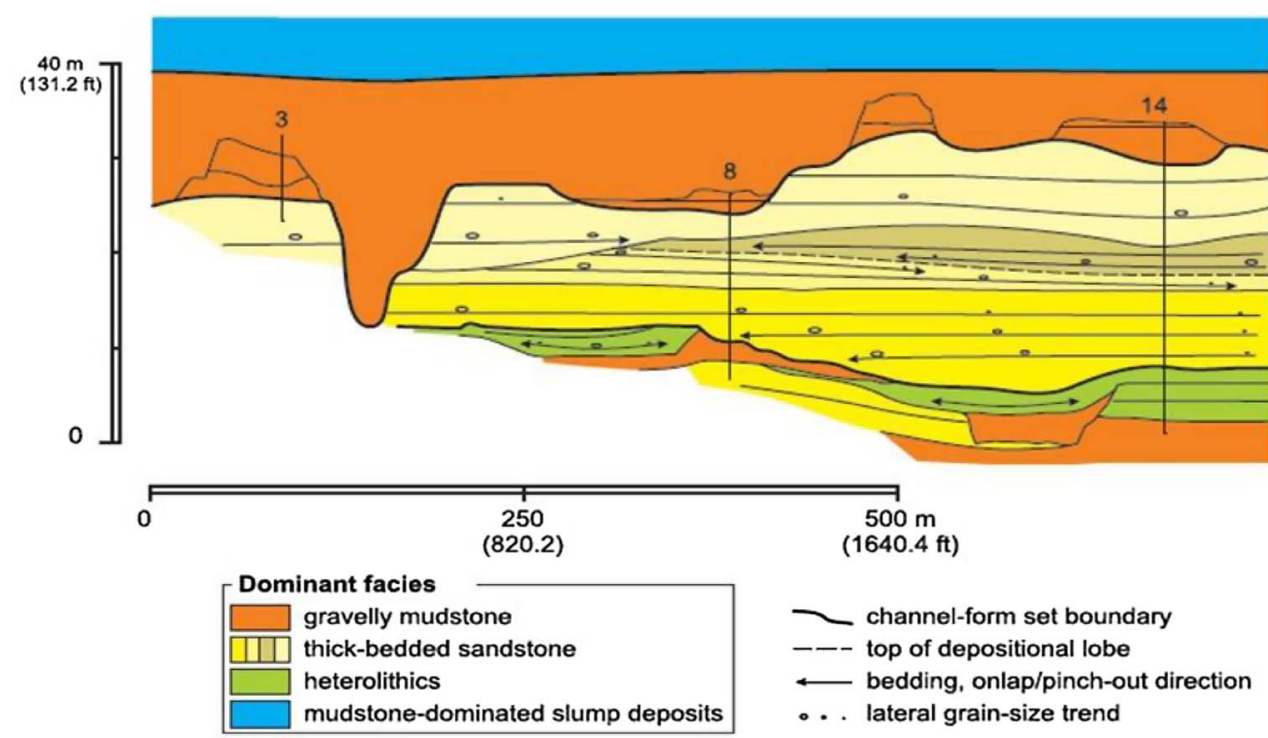

Fig. A1. Architecture of the Ainsa-1-quarry outcrop (from Arbués et al., 2007). (a) Four channels (C1.3, C2.1, C2.2, C3) are delineated and recognized inside the multi-channel complex. Wells 5, 8, 12, and 14 are locations of pseudo-wells used in the modeling study. (b) The four Ainsa units and dominant facies. 


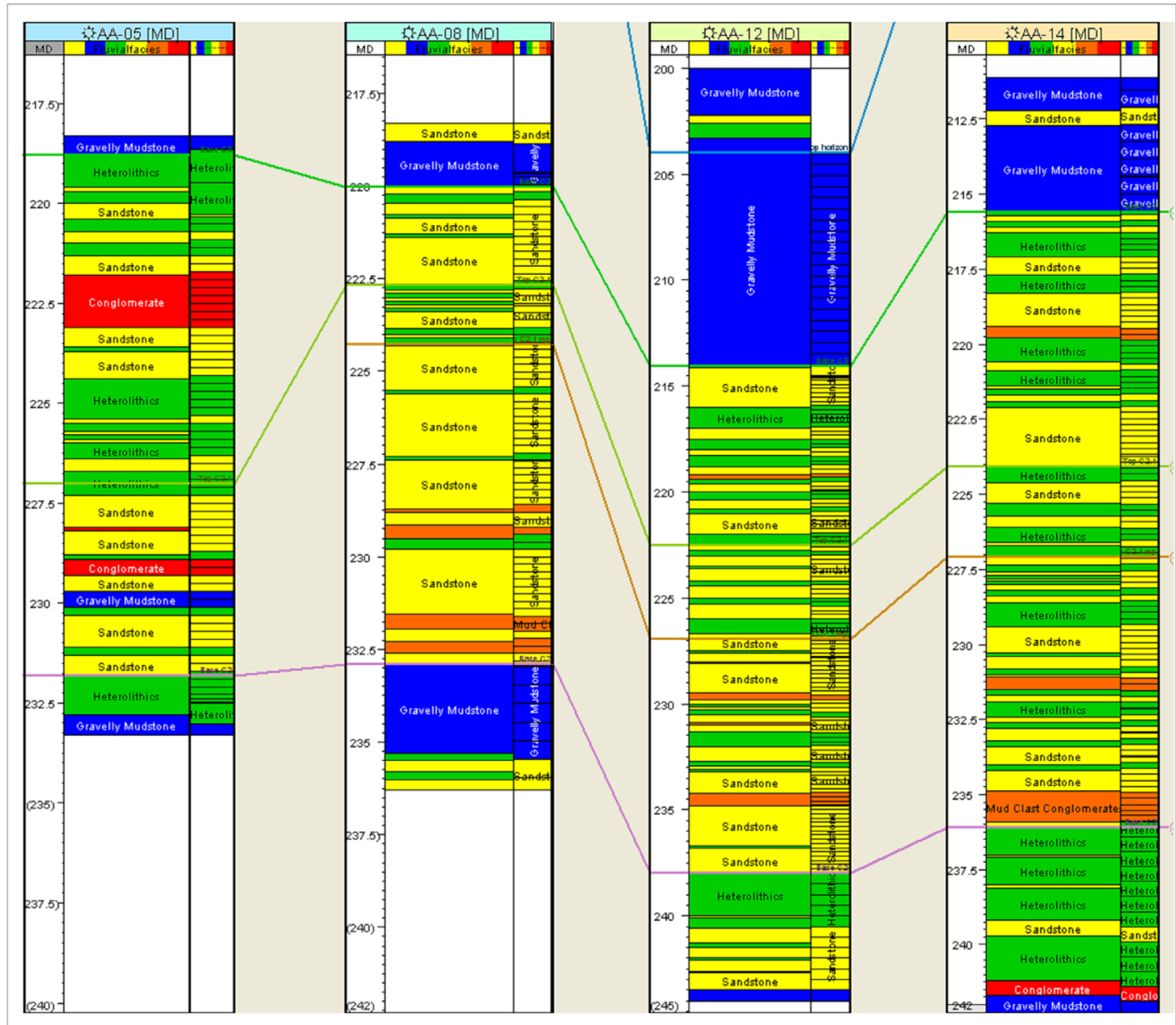

Fig. A2. Vertical well logs and their corresponding upscaled facies logs.

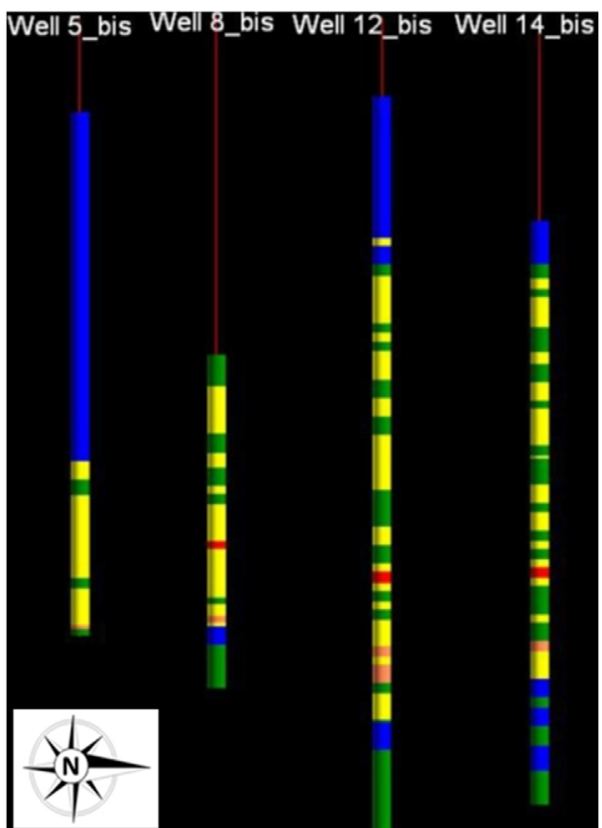

Fig. A3. Synthetic logs and facies displays in Ainsa, see Figure A2 for correspondence between color and facies. of the property distributions depend on facies as detailed in Table A1.

\section{Rock properties for flow simulation}

We used the following values for average compressibility: 2.96 for the thick-bedded sandstone, 10 for the gravelly mudstone, 90 for heterolithics, 12.4 for mudstone-clast conglomerates, and 6.51 for conglomerates, all in units of $10^{-5} \mathrm{bar}^{-1}$.

\section{Fluid properties}

The pressure dependence of the oil formation volume factor, which is the ratio of the oil volume at reservoir (in-situ) conditions to that at stock tank (surface) conditions, and the viscosity of the oil phase are plotted in Figure A4. The corresponding parameters for water are identical to that tabulated by Batzle and Wang (1992). Average oil density and water density are $853.7 \mathrm{~kg} / \mathrm{m}^{3}$ and $1012 \mathrm{~kg} / \mathrm{m}^{3}$ at surface conditions.

\section{The Kr-Pc model}

Different numerical reservoir production modeling show that thick-bedded sandstone and heterolithics have a strong impact on flow profile in the reservoir. For these two facies 
Table A1. Parameters used to populate the 3D facies model with porosity and permeability using the geostatistical distributions given in the first column. For Porosity the four displayed values are the mean/standard deviation $/ \mathrm{min}$. truncated/max. truncated values. For $K_{h}$ (horizontal permeabilities), the four values are log values of mean/standard deviation $/ \mathrm{min}$. truncated $/ \mathrm{max}$. truncated; equivalent $K_{h}$ mean value is provided in parenthesis. Vertical permeability $K_{z}$ is proportional to $K_{h}$ according to the coefficients specified in the last row.

\begin{tabular}{lccccc}
\hline & $\mathrm{gM}$ & $\mathrm{H}$ & $\mathrm{TkS}$ & $\mathrm{McC}$ & $\mathrm{C}$ \\
\hline Porosity truncated & $0 / 0.01 / 0 / 0.03$ & $0.01 / 0.01 / 0 / 0.05$ & $0.25 / 0.02 / 0.2 / 0.3$ & $0.1 / 0.03 / 0.1 / 0.3$ & $0.2 / 0.03 / 0.15 / 0.3$ \\
Gaussian & & & & & \\
Kh truncated & $10^{-10}$ & $4 / 0.3 / 2 / 5$ & $5.8 / 0.3 / 0.8 / 8$ & $1.47 / 0.45 /-1 / 7$ & $4 / 0.45 / 1.5 / 8$ \\
logNormal & $(\sim 0 \mathrm{mD})$ & $(\sim 40 \mathrm{mD})$ & $(\sim 400 \mathrm{mD})$ & $(\sim 5 \mathrm{mD})$ & $(\sim 400 \mathrm{mD})$ \\
$K_{z} / K_{h}$ & 1 & 0.1 & 1 & 0.05 & 1 \\
\hline
\end{tabular}

TkS: thick-bedded sandstone; gM: gravelly mudstone; H: heterolithics; McC: mudstone-clast conglomerates; C: conglomerates.

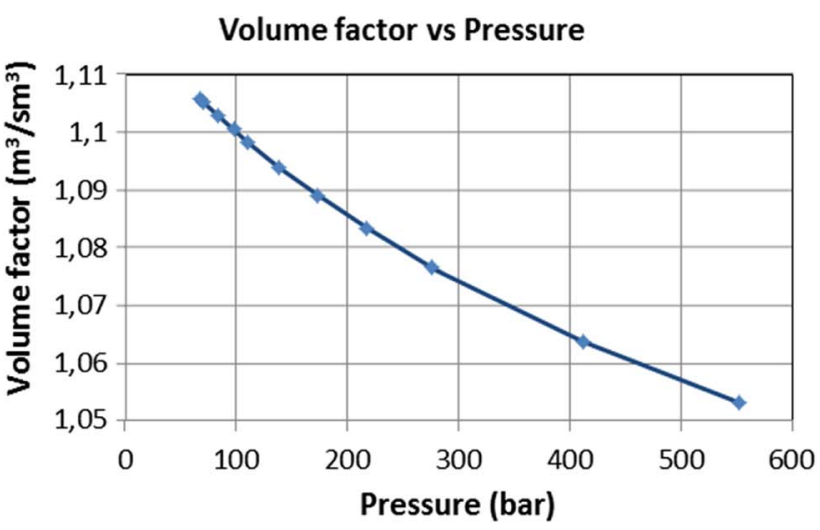

(a)

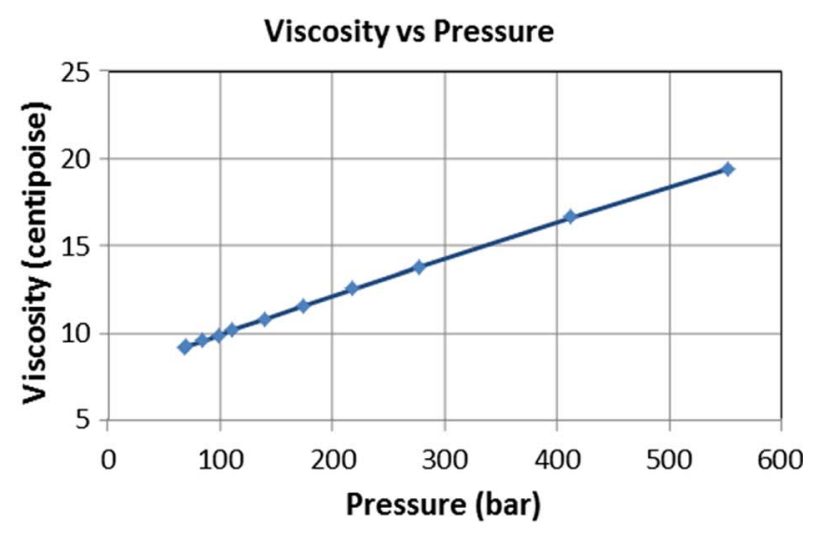

(b)

Fig. A4. (a) Volume factor and (b) viscosity of the oil phase as functions of pressure in the PVT model.

the Relative Permeability-Capillary Pressure $\left(K_{r}-P_{c}\right)$ curves are given in Figures $\mathrm{A} 5 \mathrm{a}$ and $\mathrm{A} 5 \mathrm{~b}$ respectively. Both figures are organized following the same plot convention, with capillary pressure as a function of water saturation in the top subfigure and the dependence of Relative Permeability to Oil (KRO) (red curves) and Relative Permeability to Water (KRW) (blue curves) as functions of water saturation at the bottom. The saturation range for which the two fluids are mobile is limited by the Irreducible Water Saturation (SWI) and the Residual Oil Saturation (SORW) (e.g., Zinszner and Pellerin, 2007). The end-points of the $K_{r}$ curves in this saturation range are marked by black solid disks in both figures. For convenience, the curves are linearly extrapolated to the expected extreme bounds, namely (KRO $\left.=1, S_{\mathrm{w}}=0\right)$ and $\left(\mathrm{KRO}=0, S_{\mathrm{w}}=1\right)$ for the relative permeability to oil $\mathrm{KRO}$, and $\left(\mathrm{KRW}=0, S_{\mathrm{w}}=0\right)$ and $\left(\mathrm{KRW}=1, S_{\mathrm{w}}=1\right)$ for the relative permeability to water KRW. These relative permeability and capillary pressure curves are typical of water wet rocks. For all facies, water saturation varies between $30 \%$ (SWI) and 68\% (1 - SORW) except for sandstone whose saturation varies from $15 \%$ to $75.5 \%$. Although extreme $K_{r}$ and $P_{c}$ values are the same for all facies, the broader range of water saturation variation for the thick-bedded sandstone makes it the best oil reservoir facies in terms of oil volume storage and facility to produce it (Tab. A2). We may also notice that flow velocity is controlled by both permeability and relative permeability. As a consequence, even if the $K_{r}-P_{c}$ model is the same for some facies, flow velocity within these facies will be different due to the differences in the permeability distributions. 

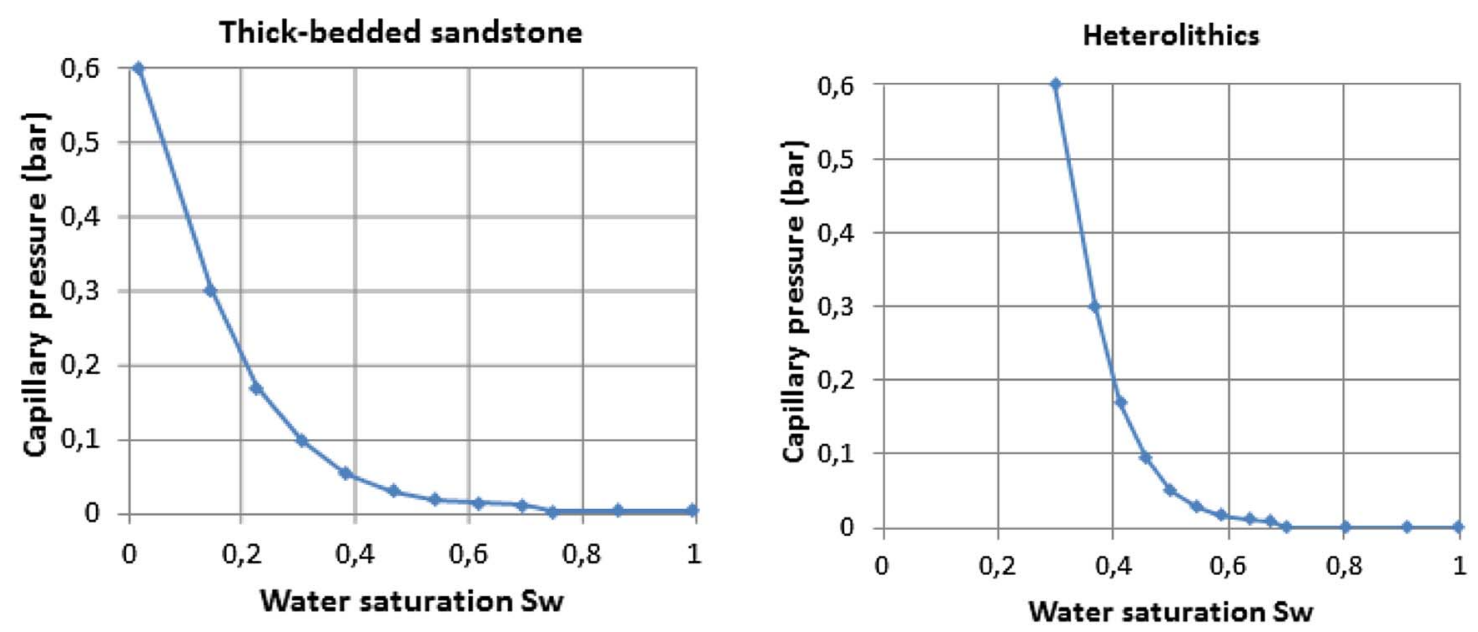

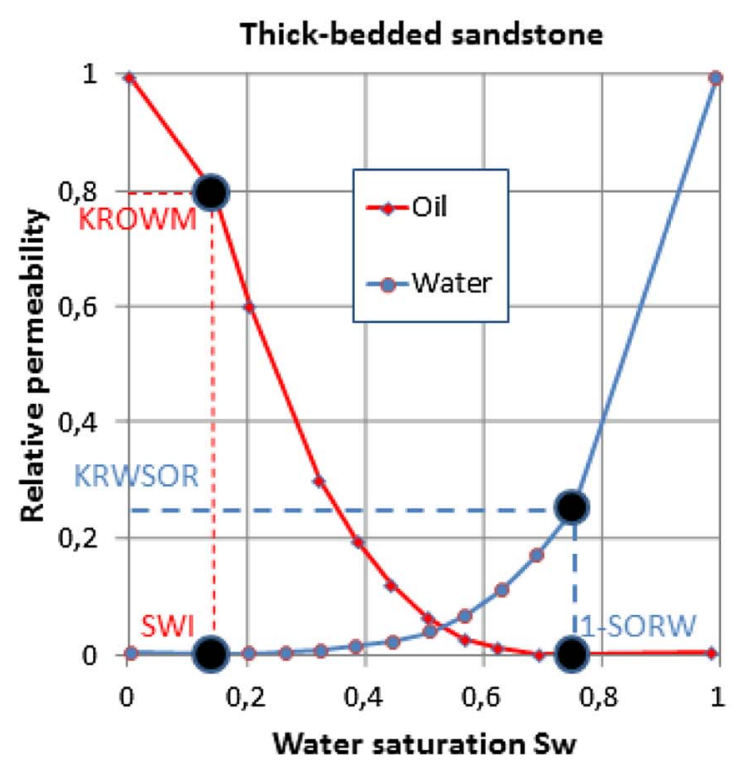

(a)

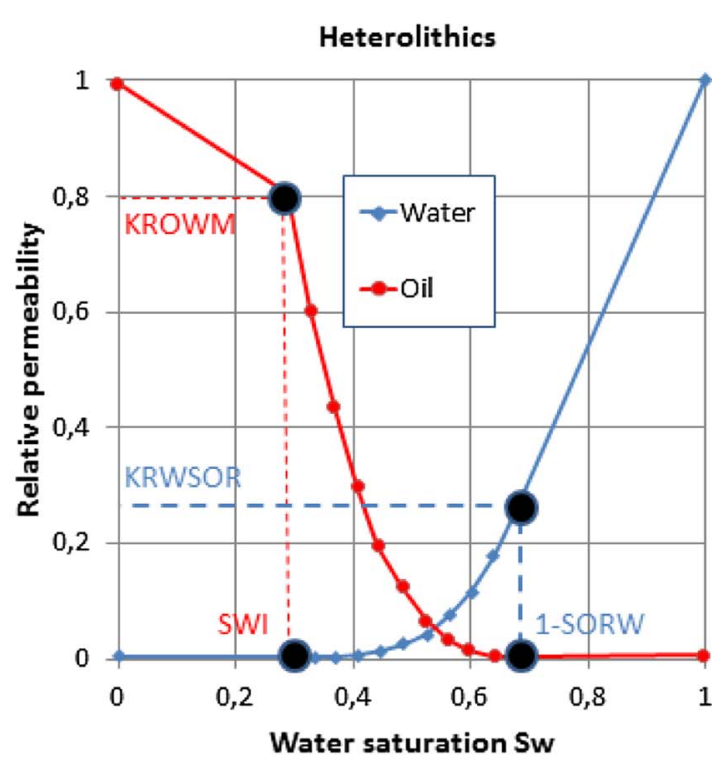

(b)

Fig. A5. Capillary pressure and Relative permeability curves for (a) thick-bedded sandstone facies and (b) heterolithics facies. SWI: irreducible water saturation; SORW: residual oil saturation to water; KROWM: relative permeability to oil at minimum water saturation; KRWSOR: relative permeability to water at residual oil saturation.

Table A2. Capillary pressure and relative permeability curves end-points.

\begin{tabular}{lcccccc}
\hline Facies & SWI & SORW & KRWSOR & KROWM & PcMax & PcMin \\
\hline gM, H, McC, C & 0.3 & 0.32 & 0.25 & 0.8 & 0.6 & 0 \\
TkS & 0.15 & 0.245 & 0.25 & 0.8 & 0.6 & 0 \\
\hline
\end{tabular}

Symbol SWI: irreducible water saturation; SORW: residual oil saturation to water; KROWM: relative permeability to oil at minimum water saturation; KRWSOR: relative permeability to water at residual oil saturation; TkS: thick-bedded sandstone; gM: gravelly mudstone; H: heterolithics; McC: mudstone-clast conglomerates; C: conglomerates.

\section{Appendix B}

\section{Production strategy}

The conditions of exploitation were chosen as realistic as possible. Target injection and production rates were imposed (Tab. B1) with pressure constraints at the injector well (maximum pressure) and producer wells (minimum pressure). As a consequence, if injector pressure increases to the maximum authorized pressure, the well bottom hole pressure is maintained to this limit pressure and the water injection rate decreases: the injector well behavior changes 
Table B1. Target injection and production rates and pressure constraints imposed to the wells.

\begin{tabular}{lccc}
\hline & $\begin{array}{c}\text { Max target injection/ } / \\
\text { production } \\
\text { rate }\left(\mathrm{m}^{3} \text { day }^{-1}\right)\end{array}$ & $\begin{array}{c}\text { Max } \\
\text { bottom hole } \\
\text { pressure } \\
\text { (bar) }\end{array}$ & $\begin{array}{c}\text { Min bottom } \\
\text { pressure } \\
\text { (bar) }\end{array}$ \\
\hline Injector & 600 & 500 & - \\
Producers & 150 & - & 67 \\
\hline
\end{tabular}

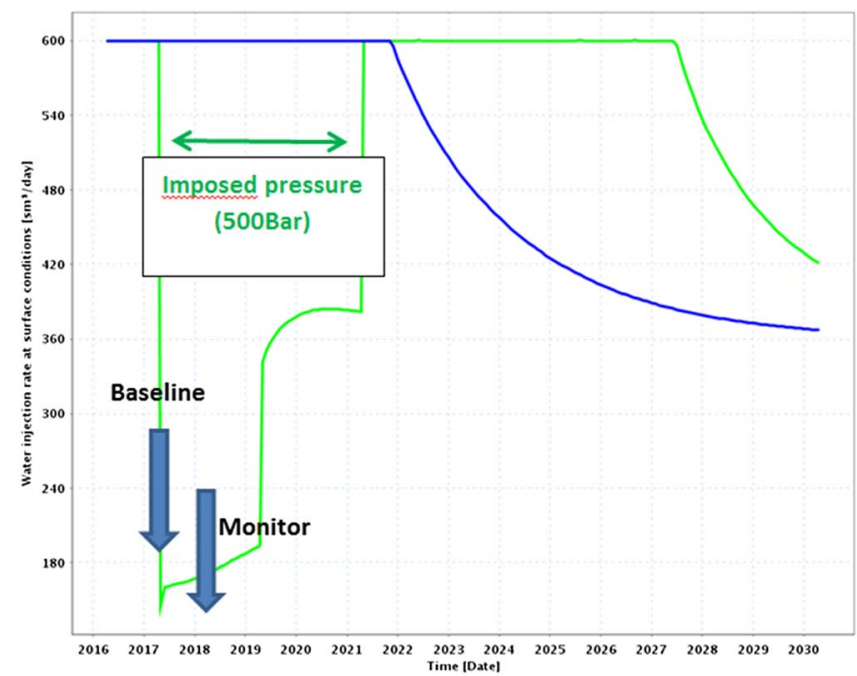

Fig. B1. Water injection rate taking into account max pressure limit for SP injection scenario in green and WF scenario in blue $\left(Q_{\max }=600 \mathrm{~m}^{3} \mathrm{~d}^{-1}\right)$.

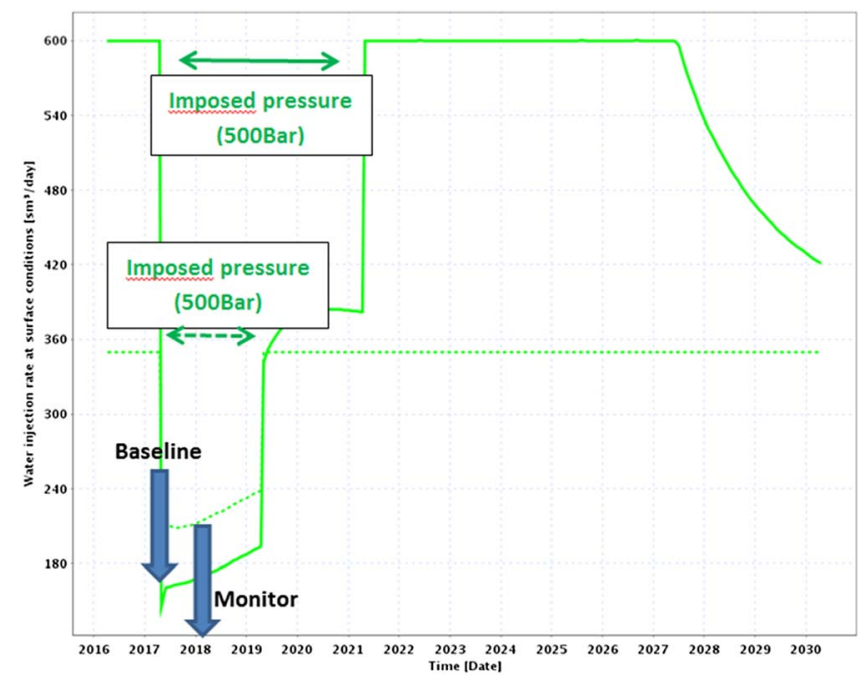

Fig. B2. Water injection rate taking into account max pressure limit for SP injection scenario and the two target injection rates $Q_{\max }=600 \mathrm{~m}^{3} \mathrm{~d}^{-1}$ and $Q_{\max }=350 \mathrm{~m}^{3} \mathrm{~d}^{-1}$ (respectively in continuous and dashed lines). from a rate control to a pressure control. This switch was observed here with polymer injection in the SP scenario (Figs. B1 and B2).

\section{Appendix C}

\section{Parameters for computing elastic properties and seismic response}

\section{Fluid substitution effect on elastic properties of rocks}

For computing the elastic properties of each facies we use the so-called Biot-Gassmann theory. Biot (1941) introduced the theory of linear elasticity of porous media, or more concisely poroelasticity. Without entering details, Gassmann (1951), using elementary elasticity, derived the explicit link between the physical parameters of Biot's macroscopic constitutive equations and the microscopic parameters of the porous medium (i.e. solid and fluid constituents, porosity):

$$
\left\{\begin{array}{r}
M^{(\mathrm{sat})}=M^{(\mathrm{dry})}+\alpha^{2} B \\
\mu^{(\mathrm{sat})}=\mu^{(\mathrm{dry})},
\end{array}\right.
$$

where:

$$
\alpha=1-\frac{M^{(\mathrm{dry})}}{M^{\text {(grain) }}},
$$

and

$$
\frac{1}{B}=\frac{\phi}{M^{(\text {fluid })}}+\frac{\alpha-\phi}{M^{(\text {grain })}},
$$

with:

$M^{\text {(sat) }}$ and $\mu^{(\mathrm{sat})}$ : bulk and shear moduli of the fluidsaturated rock;

$M^{(\mathrm{dry})}$ and $\mu^{(\mathrm{dry})}$ : bulk and shear moduli of the dry rock;

$\alpha$ : Biot's effective stress coefficient;

$\phi$ : the porosity;

$M^{\text {(grain) }}$ and $M^{\text {(fluid) }}$ : bulk moduli of the grain constituent and of the saturating fluid.

No assumption is made on the geometry of the porous network of the rock. Note also that $\alpha$ is only function of the rock structure without any fluid, while parameter $B$ is the only parameter depending on the fluid constituent through parameter $M^{\text {(fluid) }}$. Lastly, in the case of nonmiscible two-phase fluid, such as oil and water (the case we considered), the bulk modulus $M^{\text {(fluid) }}$ of the mixed fluid (assuming that pore pressure is uniform in the two-phase fluid) is given by:

$$
M^{(\text {fluid })}=\left(\frac{S_{\mathrm{o}}}{M^{\text {(oil) }}}+\frac{S_{\mathrm{w}}}{M^{(\text {water })}}\right)^{-1},
$$

with:

$M^{(\text {oil })}$ and $M^{\text {(water) }}$ : bulk moduli of oil and water respectively; 
$S_{\mathrm{o}}$ and $S_{\mathrm{w}}$ : oil saturation and water saturation.

Equations (C.1)-(C.4) are commonly called BiotGassmann equations in the geophysics literature (e.g., Bourbié et al., 1987; Calvert, 2005).

\section{Pressure effect on elastic properties of rocks}

Up to now we have ignored any pressure-dependence of any kind in the model. In fact some of the parameters introduced in equations (C.1)-(C.4) depend either on the confining pressure $P_{c}$ and/or the pore pressure $P_{p}$ : the fluid bulk modulus $M^{\text {(fluid) }}$ depends on $P_{p}$ (Batzle and Wang 1992), while the bulk and shear moduli of the dry rock $M^{(\mathrm{dry})}$ and $\mu^{\text {(dry) }}$ both depend on $P_{c}$ and $P_{p}$. However, it can be shown experimentally (e.g., Rasolofosaon and Zinszner, 2009, 2012) that these moduli essentially depend on the differential pressure $P_{\text {diff }}\left(P_{\text {diff }}=P_{c}-P_{p}\right)$ and not in an independent way on $P_{c}$ and on $P_{p}$. We use the simplest model of pressure dependence assuming a power law for the dependence of $M^{\text {(dry) }}$ and $\mu^{(\mathrm{dry})}$ with the differential pressure $P_{\text {diff: }}$

and

$$
\begin{aligned}
& \frac{M^{(\mathrm{dry})}\left(P_{\text {diff } 2}\right)}{M^{(\mathrm{dry})}\left(P_{\text {diff } 1}\right)}=\left(\frac{P_{\text {diff } 2}}{P_{\text {diff } 1}}\right)^{h_{M}} \\
& \frac{\mu^{(\mathrm{dry})}\left(P_{\text {diff } 2}\right)}{\mu^{(\mathrm{dry})}\left(P_{\text {diff } 1}\right)}=\left(\frac{P_{\text {diff } 2}}{P_{\text {diff } 1}}\right)^{h_{\mu}},
\end{aligned}
$$

with $P_{\text {diff1 }}$ and $P_{\text {diff2 }}$ corresponding to two differential pressures and $h_{M}$ and $h_{\mu}$ being the Hertz exponents of the bulk and shear moduli (experimental measurement of Hertz exponents in various types of rocks are reported by Rasolofosaon and Zinszner, 2012).

Note that we neglect any pressure dependence of the rock porosity $\phi$ and of the bulk modulus of the grain constituent $M^{\text {(grain) }}$.

\section{$P$ - and S-wave velocities and impedances of fluid-saturated rocks}

Then P- and S-wave velocities $V_{\mathrm{P}}{ }^{\text {(sat) }}$ and $V_{\mathrm{S}}{ }^{\text {(sat) }}$, and impedances $I_{\mathrm{P}}{ }^{\text {(sat) }}$ and $I_{\mathrm{S}}{ }^{\text {(sat) }}$ of the fluid-saturated rock are given by:

$$
\begin{aligned}
& V_{\mathrm{P}}^{(\mathrm{sat})}=\sqrt{\frac{M^{(\mathrm{sat})}+\frac{4}{3} \mu^{(\mathrm{sat})}}{\rho^{(\mathrm{sat})}}} ; \quad V_{\mathrm{S}}^{(\mathrm{sat})}=\sqrt{\frac{\mu^{(\mathrm{sat})}}{\rho^{(\mathrm{sat})}}}, \\
& I_{\mathrm{P}}^{(\mathrm{sat})}=\rho^{(\mathrm{sat})} V_{\mathrm{P}}^{(\mathrm{sat})} ; \quad I_{\mathrm{S}}^{(\mathrm{sat})}=\rho^{(\mathrm{sat})} V_{\mathrm{S}}^{(\mathrm{sat})},
\end{aligned}
$$

where the density $\rho^{\text {(sat) }}$ of the fluid-saturated rock is given by:

$$
\rho^{\text {(sat) }}=\phi\left(S_{\mathrm{o}} \times \rho^{(\text {oil })}+S_{\mathrm{w}} \times \rho^{(\text {water })}\right)+(1-\phi) \rho^{\text {(grain })},
$$

with $\rho^{\text {(oil) }}, \rho^{\text {(water) }}$, and $\rho^{\text {(grain) }}$ respectively designate the densities of oil, water, and grain constituent.

\section{Application to our synthetic case study}

For our monitoring feasibility study, we associated to each facies the average petroelastic parameters listed in Table C1. Using equations (C.1)-(C.8) we were able to infer the impact of fluid substitution and pressure changes on the behavior of facies elastic moduli.

First of all, Figure C1 gives the pressure dependence of the density and the bulk moduli of oil and water. As expected, water and oil exhibit a slight density increase with pressure, oil being less dense than water. Note the comparable value of the density versus pressure gradient. Similar observations can be made for the bulk modulus with the proviso that the modulus versus pressure gradient is twice larger for oil than for water: roughly

Table C1. Parameters of the Petroelastic model for each facies. The nomenclature of each facies is the one introduced in Arbués et al. (2007).

\begin{tabular}{lccccc}
\hline & Facies gM & Facies H & Facies TkS & Facies C & Facies McC \\
\hline$M^{\text {(grain) }}(\mathrm{GPa})$ & 9.5513 & 30.00 & 38.00 & 25.00 & 25.00 \\
$\mu^{\text {(grain })}(\mathrm{GPa})$ & 2.28 & 44.00 & 44.00 & 35.00 & 29.00 \\
$\rho^{\text {(grain) }}\left(\mathrm{g} \mathrm{cm}^{-3}\right)$ & 2.40 & 2.40 & 2.65 & 2.30 & 2.15 \\
$M^{\text {(dry) }}(\mathrm{GPa})$ & 9.5513 & 2.50 & 6.36 & 2.02 & 3.51 \\
$\mu^{(\mathrm{dry})}(\mathrm{GPa})$ & 2.5136 & 0.9375 & 4.08312 & 1.6463 & 1.31625 \\
$v$ & 0.379 & 0.333 & 0.235 & 0.179 & 0.333 \\
$h_{M}$ & 0.01 & 0.088 & 0.088 & 0.088 & 0.01 \\
$h_{\mu}$ & 0.01 & 0.141 & 0.141 & 0.141 & 0.01 \\
\hline
\end{tabular}

Symbol M designates the bulk modulus, $\mu$ is the shear modulus, $\rho$ is the density, $v$ is the Poisson's ratio; $h_{M}$ is the Hertz pressure-dependence coefficient for $\mathrm{M}, h_{\mu}$ is the Hertz pressure-dependence coefficient for $\mu$. Grain and dry respectively stand for the grain constituent and for the rock skeleton. TkS: thick-bedded sandstone; gM: gravelly mudstone; $\mathrm{H}$ : heterolithics; McC: mudstone-clast conglomerates; C: conglomerates. 


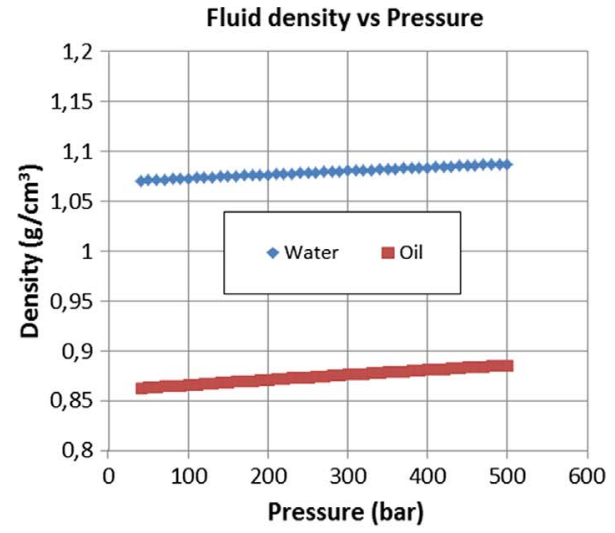

(a)

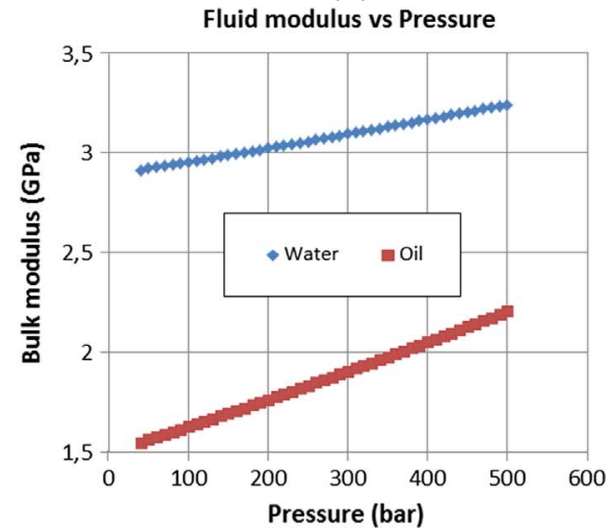

(b)

Fig. C1. Pressure dependence of (a) density and (b) bulk modulus of the saturating fluids.

$14 \times 10^{-4} \mathrm{GPa}$ /bar for oil against $7 \times 10^{-4} \mathrm{GPa} /$ bar for water, oil being expectedly more compressible than water. The systematic increase of fluid bulk modulus with fluid pressure is one of the numerous manifestations of nonlinear elastic behavior of fluids (e.g., Beyer, 1965).

The fluid pressure dependence of the shear modulus of thick-bedded sandstone and heterolithics is illustrated by Figure C2. As expected the result is independent of the saturating fluid since fluids cannot support shearing stress, as long as the fluid viscosity is not too strong, typically smaller than $10^{3}$ centipoise as demonstrated experimentally by Rasolofosaon and Zinszner (2012).

As widely known, an increase of the fluid pressure $P_{p}$, implying a decrease of the differential pressure $P_{\text {diff }}$ at fixed confining pressure $P_{c}$, induces a softening of the rock (decrease of the shear modulus shown on Fig. C2) by opening the cracks and compliant pores (e.g., Bourbié et al., 1987; Mavko et al., 1998). Note that the shear modulus vs pressure gradient is roughly four times larger for the thick-bedded sandstone $\left(23 \times 10^{-4} \mathrm{GPa} / \mathrm{bar}\right)$ than for the heterolithics $\left(5 \times 10^{-4} \mathrm{GPa} /\right.$ bar $)$.

Figure C3 shows the fluid pressure dependence of bulk moduli of fluid-saturated thick-bedded sandstone and heterolithics, for different levels of oil saturation $S_{0}$. The results are less obvious for the bulk modulus than for the shear modulus. More precisely, in the case of the thick-bedded

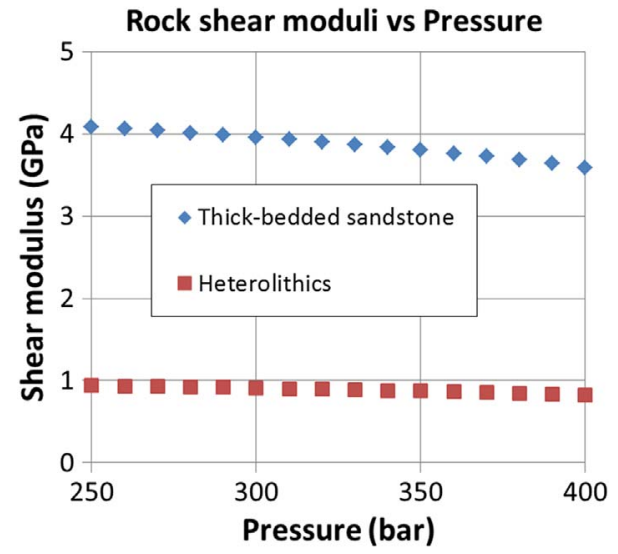

Fig. C2. Pressure dependence of the shear moduli of the two facies that control the flow profile in the reservoir, namely the thick-bedded sandstone and the heterolithics, for any saturating fluid.

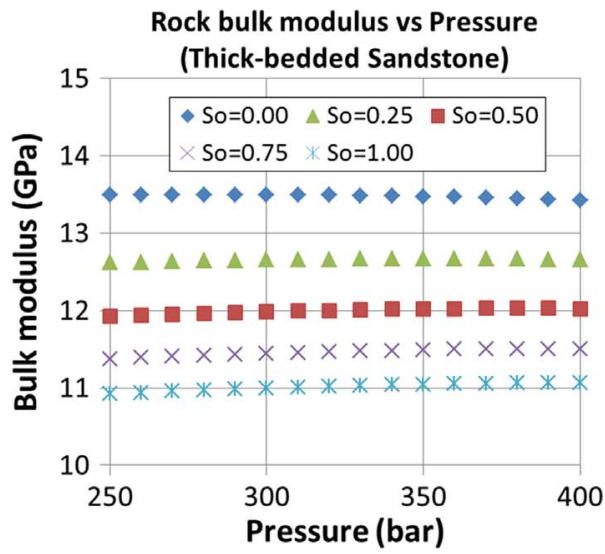

(a)

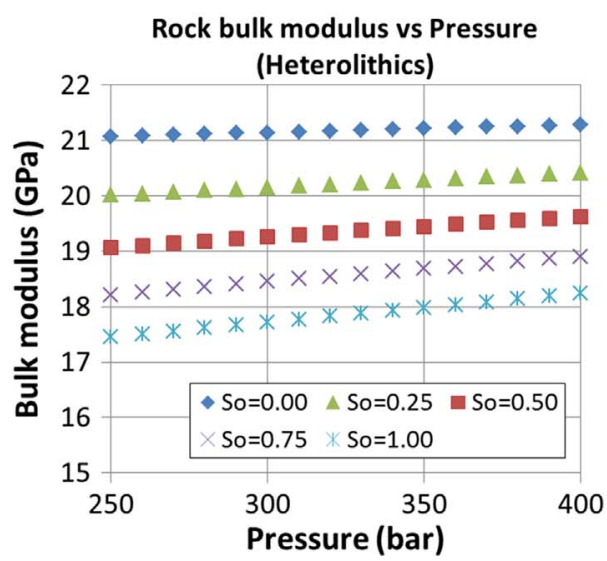

(b)

Fig. C3. Pressure dependence of the bulk moduli of the two facies that control the flow profile in the reservoir, namely (a) thick-bedded sandstone and (b) heterolithics, for different levels of oil saturation $S_{\mathrm{o}}$.

sandstone a slight increasing trend of the bulk modulus with fluid pressure is observed at large oil saturation (typically for $S_{\mathrm{o}}>0.75$ ), whereas a slight decreasing trend 
is exhibited at small $S_{\mathrm{o}}$ (typically for $S_{\mathrm{o}}<0.25$ ). In contrast the heterolithics exhibit a simpler behavior with a systematic increasing trend of the bulk modulus with fluid pressure. In fact this is due to two competing effects. On the one hand, as previously described, an increase of $P_{p}$, tends to soften the rock (decrease of the bulk modulus) by opening the cracks and compliant pores. On the other hand, an increase of $P_{p}$ tends to increase the fluid bulk modulus of the saturating fluid, as illustrated by Figure C1, which tends to stiffen the fluid-saturated rock. In the heterolithics the second effect clearly dominates. In contrast in the thick-bedded sandstone for large oil saturation, the softening effect due to crack opening slightly dominates the stiffening effect due to nonlinear elasticity of the saturating fluid. For low oil saturation the dominating effect of fluid nonlinear elasticity is re-established. Note that a quasi-linear increase of the bulk modulus of the fluid-saturated rock with $M^{\text {(fluid) }}$ can be deduced from equations (C.1) to (C.3), under the stiff-grain assumption
$\left(M^{\text {(grain) }} \gg M^{(\text {fluid })}\right)$, and was observed experimentally (Rasolofosaon and Zinszner, 2012).

In conclusion, in our case, fluid substitution induces substantially larger variation of fluid-saturated rock bulk modulus $M^{\text {(sat) }}$ than fluid pressure variation. For instance, pressure-induced variation of $M^{\text {(sat) }}$ hardly exceeds $5 \%$ for the heterolithics, and even $1.5 \%$ for the thick-bedded sandstone, in the most extreme case, namely in the case of full-oil saturation $\left(S_{\mathrm{o}}=1\right)$. In contrast, the variations of $M^{\text {(sat) }}$ induced by substitution of oil by water can reach up to $23 \%$ for the thick-bedded sandstone and $20 \%$ for the heterolithics.

Lastly, because $\mathrm{P}$-wave velocity $V_{\mathrm{P}}{ }^{\text {(sat) }}$ and impedances $I_{\mathrm{P}}{ }^{\text {(sat) }}$ of the fluid-saturated rock are functions of both bulk modulus $M^{\text {(sat) }}$ and shear modulus $\mu^{\text {(sat) }}$, they also exhibit rather complicated variations with fluid pressure and fluid content. The consequences on seismic responses are extensively illustrated in the main text of this paper. 